\title{
A computer-simulated mechanism of familial Alzheimer's disease: Mutations enhance thermal dynamics and favor looser substrate-binding to -secretase
}

Dehury, Budheswar; Somavarupu, Arun K; Kepp, Kasper Planeta

Published in:

Journal of Structural Biology

Link to article, DOI:

10.1016/j.jsb.2020.107648

Publication date:

2020

Document Version

Peer reviewed version

Link back to DTU Orbit

Citation (APA):

Dehury, B., Somavarupu, A. K., \& Kepp, K. P. (2020). A computer-simulated mechanism of familial Alzheimer's disease: Mutations enhance thermal dynamics and favor looser substrate-binding to -secretase. Journal of Structural Biology, 212(3), [107648]. https://doi.org/10.1016/j.jsb.2020.107648

\section{General rights}

Copyright and moral rights for the publications made accessible in the public portal are retained by the authors and/or other copyright owners and it is a condition of accessing publications that users recognise and abide by the legal requirements associated with these rights.

- Users may download and print one copy of any publication from the public portal for the purpose of private study or research.

- You may not further distribute the material or use it for any profit-making activity or commercial gain

- You may freely distribute the URL identifying the publication in the public portal 


\section{Journal Pre-proofs}

A computer-simulated mechanism of familial Alzheimer's disease: Mutations enhance thermal dynamics and favor looser substrate-binding to $\gamma$-secretase

Budheswar Dehury, Arun K. Somavarupu, Kasper P. Kepp

PII:

S1047-8477(20)30221-5

DOI:

https://doi.org/10.1016/j.jsb.2020.107648

Reference: $\quad$ YJSBI 107648

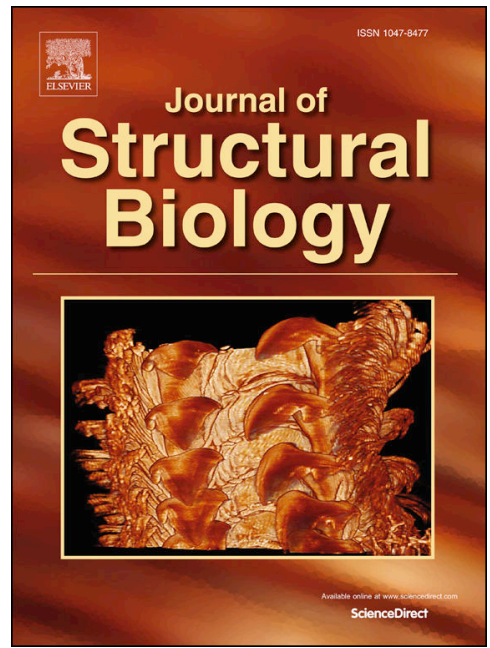

To appear in:

Journal of Structural Biology

Received Date: $\quad 24$ June 2020

Revised Date: $\quad 22$ September 2020

Accepted Date: $\quad 9$ October 2020

Please cite this article as: Dehury, B., Somavarupu, A.K., Kepp, K.P., A computer-simulated mechanism of familial Alzheimer's disease: Mutations enhance thermal dynamics and favor looser substrate-binding to $\gamma$ secretase, Journal of Structural Biology (2020), doi: https://doi.org/10.1016/j.jsb.2020.107648

This is a PDF file of an article that has undergone enhancements after acceptance, such as the addition of a cover page and metadata, and formatting for readability, but it is not yet the definitive version of record. This version will undergo additional copyediting, typesetting and review before it is published in its final form, but we are providing this version to give early visibility of the article. Please note that, during the production process, errors may be discovered which could affect the content, and all legal disclaimers that apply to the journal pertain.

(C) 2020 Elsevier Inc. All rights reserved. 


\section{A computer-simulated mechanism of familial Alzheimer's disease: Mutations} enhance thermal dynamics and favor looser substrate-binding to $\gamma$-secretase

Budheswar Dehury ${ }^{1}$, Arun K. Somavarupu ${ }^{2}$ and Kasper P. Kepp ${ }^{1 *}$

${ }^{1}$ Department of Chemistry, Technical University of Denmark, DK-2800 Kongens Lyngby,

Denmark

${ }^{2}$ Interdisciplinary Nanoscience Center (iNANO), Aarhus University, Gustav Wieds Vej 14, DK 8000 Aarhus C, Denmark

*Corresponding Author.E-mail: kpj@kemi.dtu.dk. Phone: +045 45252409

\section{ORCID ID:}

Budheswar Dehury: 0000-0002-9726-8454

Arun K. Somavarupu: 0000-0001-6123-6875

Kasper P. Kepp: 0000-0002-6754-7348 


\section{Abstract}

The 4-subunit intramembrane protease complex $\gamma$-secretase cleaves many substrates including fragments of the $\beta$-amyloid precursor protein (APP), leading to formation of $\mathrm{A} \beta$ peptides, and Notch. Mutations in APP and the catalytic subunit of $\gamma$-secretase, presenilin, cause familial Alzheimer's disease (fAD). Mutations are assumed to change the substrate-binding and cleavage and thereby the $A \beta$ formed. Whereas a wild-type structure of substrate-bound $\gamma$-secretase became recently available from cryogenic electron microscopy (6IYC), the structure and dynamics of mutant proteins remain obscure. Here, we studied five prominent mutants of substrate-bound $\gamma$ secretase by explicit all-atom molecular dynamics in a phospholipid membrane model at physiological temperature using the experimental structure as template: The presenilin 1 mutants E280A, G384A, A434C, and L435F and the V717I mutant of APP. Our structures and dynamics provide the first atomic detail into how fAD-causing mutations affect substrate binding to $\gamma$ secretase. The pathogenic mutations tend to increase the space and variability in the substrate binding site, as seen e.g. from the distance from catalytic aspartate to substrate cleavage sites. We suggest that we have identified the molecular cause of the "imprecise cleavage" that leads to two trimming pathways in $\gamma$-secretase, consistent with the FIST model, which may rationalize the experimental $\mathrm{A} \beta_{42} / \mathrm{A} \beta_{40}$ ratios as a molecular basis for $\mathrm{fAD}$.

Keywords: $\gamma$-secretase; Alzheimer's disease; presenilin; mutation; molecular dynamics 


\section{Introduction}

Alzheimer's disease (AD) affects more than 30 million people, is considered a major global cause of death, and inflicts a terrible and gradual loss of memory, cognition, daily activity, identity, and mood; treatments remain symptomatic and typically only delay disease progression by some months.(Ballard et al., 2011; Holtzman et al., 2012; Selkoe, 2001; Tanzi, 2012) The accumulation of toxic, aggregation-prone $\mathrm{A} \beta$ peptides inside cells as oligomers, and ultimately as senile plaques outside the neurons, is a persistent hallmark and widely assumed to contribute to disease.(Hardy and Higgins, 1992; Masters et al., 1981; Tanzi and Bertram, 2005)

Most AD cases are sporadic with age being the most significant risk factor. However, rare mutations in the genes coding for the $\beta$-amyloid precursor protein (APP) and presenilin 1 or 2 (PS1/2) cause particularly severe, early-onset familial AD (fAD).(Brouwers et al., 2008; Campion et al., 1999; De Strooper et al., 2012) The most persistent biochemical phenotype of the fAD mutations is an increase in the relative amounts of long vs. short peptides, e.g. the $A \beta_{42} / A \beta_{40}$ ratio,(Kelleher and Shen, 2017; Sun et al., 2016) although APP mutations display very mixed phenotypes, with some increasing, others lowering the amount of A $\beta$.(Tiwari and Kepp, 2016) Despite the unavoidable scatter in clinical and biochemical data, the $A \beta_{42} / A \beta_{40}$ ratio of PS1 and PS2 mutations is strongly associated with lower catalytic activity(Sun et al., 2016) and earlier clinical onset of (i.e. more severe, after reanalysis of the data) disease.(Tang and Kepp, 2018) Accordingly, a change in $\gamma$-secretase leading to this type of effect is currently the strongestsupported mechanism of FAD.

$\gamma$-secretase is a 4-subunit intramembrane aspartyl protease whose catalytic subunit is PS1

or PS2; the other subunits are Nicastrin (NCT), Anterior pharynx-defective 1 (APH1-A/B) and Presenilin enhancer 2 (PEN2).(Knappenberger et al., 2004; Sun et al., 2015) It is responsible for proteolytic cleavage of more than 100 type-1 membrane proteins as substrates.(Beel and Sanders, 
2008; Knappenberger et al., 2004) The assembled $\gamma$-secretase complexes undergo auto-proteolytic activation of PS1/2 to generate a multimeric active protease with an N-terminal and C-terminal PS fragment (NTF, CTF).(Li et al., 2013) The large hydrophilic maturation loop breaks after being cleaved in the active site, enabling access of other substrates to the catalytic binding site, as inferred by computational comparison of mature and immature PS1 states.(Somavarapu and Kepp, 2016a) Membrane-bound APP is cleaved by $\beta$-secretase to produce the C-terminal APP fragment C99, which is then cleaved by $\gamma$-secretase in a consecutive tripeptide cleavage mechanism to produce A $\beta$ peptides of different lengths.(Fukumori et al., 2010; Kamp et al., 2015; Langosch and Steiner, 2017; Steiner et al., 2018; Takami et al., 2009) The first cleavage generates $A \beta_{49}$ or $A \beta_{48}$, with some being released and some further trimmed by sequential cuts via two proteolytic pathways i.e., $\mathrm{A} \beta_{49} \rightarrow \mathrm{A} \beta_{46} \rightarrow \mathrm{A} \beta_{43} \rightarrow \mathrm{A} \beta_{40} \rightarrow \mathrm{A} \beta_{37}$ and $\mathrm{A} \beta_{48} \rightarrow \mathrm{A} \beta_{45} \rightarrow \mathrm{A} \beta_{42} \rightarrow \mathrm{A} \beta_{38}$.(Bolduc et al., 2016b; Takami et al., 2009; Wolfe, 2020)

The mechanism by which PS1 and APP mutations cause fAD by changing $\gamma$-secretase cleavage has been intensely debated, with both loss and gain of function proposed. Loss of function(Saura et al., 2004; Shen and Kelleher, 2007) centers on reduced activity of hypomorphic $\gamma$-secretase mutations, which would impair Notch signaling(Bentahir et al., 2006; van Es et al., 2005) and disturb the normal physiological functions of $A \beta$ and other cleavage products.(Kepp, 2016) Indeed, full enzyme inactivation leads to memory impairment and neurodegeneration.(Shen and Kelleher, 2007; Xia et al., 2015) Gain of toxic function, as implied by the amyloid hypothesis, centers on changes in $A \beta$ production that induce toxic oligomers.(Eisenberg and Jucker, 2012; Selkoe and Hardy, 2016) probably via longer A $\beta$ peptides that may be locally (but rarely globally) enriched and could seed the oligomers that may cause disease.(Borchelt et al., 1996; Kepp, 2017; Scheuner et al., 1996) 
To explain the mechanism of disease of fAD mutations, chemoinformatic studies and molecular simulations of membrane-embedded $\gamma$-secretase identified an open, semi-open, and a closed conformation state with respect to the size of the catalytic pocket, and it was noted that most of the PS1 mutations tend to reduce the stability of the protein complex and reduce the hydrophobic packing, consistent with a bias towards the more open state. This open state was speculated to bind C99 less well, making all the binding constants smaller for the consecutive substrates,(Somavarapu and Kepp, 2017) and leading to earlier release of longer, more toxic A $\beta$, peptides.(Somavarapu and Kepp, 2017, 2016b, 2016a) Consistent with this analysis, several PS1 mutations destabilize the $A \beta-\gamma$-secretase complexes thereby leading to release of longer $A \beta$ peptides and higher $A \beta_{42} / A \beta_{40}$ ratios.(Szaruga et al., 2017)

According to the FIST (Fit-Stay-Trim) model,(Somavarapu and Kepp, 2017, 2016b; Tang et al., 2018) the substrate must fit (in terms of binding affinity) in order to stay long enough to be trimmed to the shortest peptides. Looser holding of C99 by the PS1 "fist" in the open conformation state leads to less stable enzyme-substrate complexes, more imprecise cleavage, and earlier release of longer $A \beta$ peptides along both pathways, whereas the closely packed conformation state leads to tight squeezing, more precise cleavage mainly along the $\mathrm{A} \beta_{40}$ pathway, i.e. normal wild-type processing. Chemo- and bioinformatics studies imply that PS1 and PS2 mutations reduce the stability of the protein and favor the open conformation state.(Dehury et al., 2019a; Mehra and Kepp, 2019; Somavarapu and Kepp, 2016b; Tang et al., 2019) In contrast, $\gamma$ secretase modulators conversely lower the $A \beta_{42} / A \beta_{40}$ ratio by contributing their binding affinity to the stability of the ternary enzyme-substrate-modulator complex, thereby favoring the compact state, according to this model.(Tang et al., 2018)

Recently, cryo-electron microscopy (cryo-EM) structures of $\gamma$-secretase both with and without substrates bound have revealed the overall architecture of the proteins and show that PS1 
exists in different conformational states.(Bai et al., 2015b, 2015a; Lu et al., 2014; Yang et al., 2019; Zhou et al., 2019) Photoaffinity substrate probes targeting the substrate binding site of $\gamma$ secretase show that FAD-linked PS1 mutations alter the interactions between PS1 and C99.(Fukumori and Steiner, 2016) Although these wild-type structural and biochemical data and non-structural bioinformatics data(Mehra and Kepp, 2019; Tang et al., 2019) support the FIST model, no actual structure of PS1 mutants has been published. The relevant conformational dynamics at physiological temperature in a membrane are much expanded compared to the frozen cryo state.(Mehra et al., 2020) All-atom molecular dynamics (MD) simulations have thus contributed the room-temperature membrane dynamics of wild-type $\gamma$-secretase as a necessary supplement to the cryo-structures.(Aguayo-Ortiz et al., 2017; Aguayo-Ortiz and Dominguez, 2018; Dehury et al., 2019b, 2019c, 2019a; Hitzenberger and Zacharias, 2019; Mehra et al., 2020; Somavarapu and Kepp, 2017) Along this progress, identifying the structures and dynamics of actual substrate-bound mutant structures are of major importance, as pursued in the present work.

To understand the effect of mutation on substrate binding to $\gamma$-secretase, we used the experimental 6IYC structure and restored it to wild type (WT) and simulated five mutations (PS1E280A, PS1-G384A, PS1-A434C, PS1-L435F and APP-V717I) with three independent simulations for each. The mutants were selected based on prominence in previous reports. They tend to increase the $A \beta_{42} / A \beta_{40}$ ratio in assays and otherwise impair the proteolytic processing of APP and Notch-1(Heilig et al., 2010; Sun et al., 2016; Szaruga et al., 2017).

E280A (the Paisa mutation) is the most frequent variant causing fAD.(Lopera et al., 1997; Sepulveda-Falla et al., 2012) It increases the $A \beta_{42} / A \beta_{40}$ ratio(Li et al., 2016; Soto-Mercado et al., 2020; Sun et al., 2016) an causes premature dissociation of $A \beta$ fragments in good accordance with the FIST Model, and thus serves as a central test case for our study.(Szaruga et al., 2017) 
Gly384 is positioned in the GxGD motif anchoring the TM domains of C83 and Notch100 via hydrogen bonding.(Yang et al., 2019; Zhou et al., 2019) G384A decreases the efficiency of $\gamma$ secretase, leading to increased $A \beta_{42}$ and reduced $A \beta_{40}$ with an associated elevated $A \beta_{42} / A \beta_{40}$ ratio,(Bentahir et al., 2006; De Jonghe et al., 2001; Li et al., 2016; Sun et al., 2016) in good accordance with the FIST model that implies that slower enzyme activity increase the $A \beta_{42} / A \beta_{40}$ ratio.(Somavarapu and Kepp, 2017, 2016b) Fluorescence lifetime imaging microscopy shows that G384A causes conformational change in PS1 thereby affecting the positioning of C99 within the active site.(Berezovska et al., 2005)

The third mutant A434C affects a site located in the PAL motif implicated in substrate recognition(Sato et al., 2008; Zhou et al., 2019), making it a relevant test case for the dynamic effects of the PAL motif. The mutant is also associated with increased $A \beta_{42}$ and decreased $A \beta_{40}$ production, and thus a 10 -fold increase in the $A \beta_{42} / A \beta_{40}$ ratio.(Sun et al., 2016)

The fourth mutant L435F also forms a part of crucial PAL motif but has been reported to be sensitive to increased temperature(Szaruga et al., 2017) and lead to longer $A \beta$, including $\mathrm{A} \beta_{43}$.(Kretner et al., 2016; Oakley et al., 2020; Tambini and D’Adamio, 2020; Veugelen et al., 2016) This distinct behavior makes it of interest as a second PAL mutant in our study.

Finally, we also studied a substrate mutant V717I (the APP London mutation), a common APP mutation. V717I increases the $A \beta_{42} / A \beta_{40}$ ratio and $A \beta_{42}$ levels with little effect on $A \beta_{40}$. (De Jonghe et al., 2001; Eckman et al., 1997; Herl et al., 2009; Theuns et al., 2006) This makes it an interesting test case for a similar mechanism caused by another gene (APP) involved in the same process and location, and was thus also studied in this work. 


\section{Computational methods}

\section{Preparation of structural models}

The published cryo-EM structure of $\gamma$-secretase bound to APP-C83 (PDB: 6IYC) was used to produce all the studied models. Since the experimental structure contains the D385A mutation to avoid turnover during data collection, we converted back this mutation to wild type computationally with the PyMOL Mutagenesis Wizard.(DeLano, 2002) Similarly, the Q112C mutation of PS1 used for cysteine crosslinking was reverted to wild type. The structural models of the PS1 mutants E280A, G384A, A434C, and L435F were generated using the same site-directed mutagenesis protocol of PyMOL.(DeLano, 2002) We also produced the V717I mutant structure of APP-C 83 bound to $\gamma$-secretase by mutating valine to isoleucine. The protein residues were assigned their standard protonation states at $\mathrm{pH}=7.4$ and missing side chains were assigned using the WHATIF server(Hekkelman et al., 2010). We note that the missing N-terminal residues of the substrate in the experimental structure were not modeled in, and thus we avoid artefacts of adding hypothetic coordinates but potentially also miss a real effect if these atoms contribute differently to mutant binding.

In our study, the catalytic residues Asp257 and Asp385 of PS1 are represented by their deprotonated states, as supported by $\mathrm{pK}_{\mathrm{a}}$ calculations of experimental and simulated structures.(Mehra et al., 2020; Mehra and Kepp, 2020) Several important simulation studies have explored possible protonated aspartates, which tend to imply shorter Asp-Asp distances, as an analogy to standard aspartyl protease mechanisms where a proton moves to Asp to enhance the water nucleophile.(Aguayo-Ortiz et al., 2019, 2017; Bhattarai et al., 2020; Hitzenberger and Zacharias, 2019) Since is important to compare studies of both situations, we emphasize the that the deprotonated state, which produces Asp-Asp distances close to the cryo-EM data, was studied. 
Each structural model was oriented according to the Orientation of Proteins in Membranes Database(Lomize et al., 2006, 2012). Each membrane-oriented protein was embedded in a 1palmitoyl-2-oleoyl-sn-glycero-3-phosphocholine (POPC) bilayer using the CHARMMGUI(Cheng et al., 2015). The system charges were electro-neutralized and then, because of the importance of salt to protein dynamics and structural stability,(Baldwin, 1996; Bauduin et al., 2004; Jensen, 2008) we added separate ions to a final concentration of $0.15 \mathrm{M} \mathrm{NaCl}$ by random Monte-Carlo ion placement. The resulting structural files were used an input for our simulations. The simulation systems are summarized in Table S1.

\section{Simulation Protocol}

All MD simulations reported in this work were carried out using GROMACS version 2019.4(Abraham et al., 2015) with the CHARMM36m force-field(Huang et al., 2016; Klauda et al., 2010) and the TIP3P explicit three-site water model.(Jorgensen et al., 1983) All simulations were performed on the graphical processing units at the DTU high-performance computing cluster, Denmark. Initial energy minimization followed the same standard six-step equilibration protocol applied to all membrane-protein-water systems at $303.15 \mathrm{~K}$ and 1 bar pressure.

Production simulations were carried out at $303.15 \mathrm{~K}$ and 1 bar using a Nose-Hoover thermostat(Martyna et al., 1992) with a coupling constant of 1 ps and a Parrinello-Rahman barostat(Parrinello and Rahman, 1981) with a time constant of 5 ps using the Verlet cutoff scheme(Páll and Hess, 2013). Long-range electrostatic interactions were calculated by the particle mesh Ewald method(Essmann et al., 1995), while the short-range electrostatic and van der Waals interactions were calculated with a cut-off of $1.2 \mathrm{~nm}$. Periodic boundary conditions were applied to all simulations, and bonds involving hydrogen atoms were constrained using the linearconstraint-solving (LINCS) algorithm(Hess et al., 1997). Each structure was subjected to three 
statistically independent simulations using 2-fs time steps for $500 \mathrm{~ns}$ via randomized initial velocity seeds. Trajectory data were saved at time intervals of 200 ps. Data analysis and visualization were conducted using visual molecular dynamics (VMD)(Humphrey et al., 1996), BIOVIA Discovery Studio Visualizer version 4.5 (BIOVIA DSV), PyMOL, Grace and other builtin tools in GROMACS.(Abraham et al., 2015)

\section{Analysis of trajectories}

The membrane parameters, including deuterium order parameters $\left(\mathrm{S}_{\mathrm{cd}}\right)$ and the densities of the membrane components, were analyzed over the full trajectories of the protein-water-membrane systems using the built-in modules gmx order and gmx density of GROMACS. In protein-lipidwater systems, we computed the density profile of the POPC head, tail, and phosphate groups and of water using the tool gmx density. The FATSLiM program(Buchoux, 2017) was employed to compute the membrane area, area per lipid, and membrane thickness. Backbone structural rootmean-squared deviations along the trajectories (RMSD), the radius of gyration $\left(\mathrm{R}_{\mathrm{g}}\right)$, and the solvent accessible surface area (SASA) averaged over the three independent simulations were computed using the gmx rms, gmx gyrate and gmx sasa tools, respectively. The root-mean-squared fluctuations (RMSF) of the C $\alpha$-atoms were analyzed for each subunit of all systems with the $g m x$ rmsf tool. The $\mathrm{C} \alpha$ distance and minimum distance between any two atoms of the catalytic Asp257 and Asp385 were computed using the gmx distance and gmx mindist programs. The hydrogen bonds were calculated using the gmx hbond utility with a donor and acceptor distance of $0.35 \mathrm{~nm}$ and a hydrogen-donor-acceptor angle cut-off of $30^{\circ}$.

In order to understand the conformational states in more detail, we performed clustering analysis of the last, equilibrated 300 ns of all 18 trajectories using the RMSD-based gmx cluster tool with a cut-off of $0.2 \mathrm{~nm}$ with the last $300 \mathrm{~ns}$ trajectories. In each case, the top-ranked structure 
(most representative of the trajectory) was analyzed below. The free-energy landscape (FEL) was generated to identify representative low-energy conformations, using the GROMACS gmx sham tool, and plotting the landscape using Origin Pro. The large concerted motions were analyzed by extracting the top principal components (PCs) using MODE-TASK(Ross et al., 2018). PCA by singular-value decomposition on $\mathrm{C} \alpha$-atoms was performed using the last $300 \mathrm{~ns}$ of each trajectory. The lipid binding occupancy (percentage of frames where lipid was in contact with any amino acid), the duration of interaction, and the lipid counts (average number of lipid surrounding a residue) were determined using the python code PyLipID (https://github.com/wlsong/PyLipID). All the helical properties were analyzed using the gmx bundle, gmx helix, or gmx helixorient tools of GROMACS. The GROMCAS module gmx do_dssp, which explicitly uses DSSP version 2.0 (http://swift.cmbi.ru.nl/gv/dssp), was used to monitor evolution of secondary structure elements during the equilibrium phase (with the last 300 ns trajectories) of each MD system. 


\section{Results and discussion}

\section{Simulated structures compared to experimental cryo-EM structures}

Recent cryo-EM structures (6IYC and 6IDF) have shown that both the catalytic subunit PS1 and the substrate undergo noticeable conformational changes upon substrate binding.(Yang et al., 2019; Zhou et al., 2019) The most significant effect of binding of C83 is arguably the supposed partial unwinding at the C-terminal turn of substrate TM helix, exposing the peptide bonds Thr719/Leu720 and Leu720/Val721 to potential attack by the nucleophilic water molecule. At the same time, the segment Val721-Lys725 of the substrate C83 has features that resemble a $\beta$ strand in close connection with two other substrate-induced strands in PS1, which together form a threestranded $\beta$-sheet in the cryo data. The significance of this sheet at physiological temperature has been debated, since it is subject to partial thermal unzipping, but the real composition of the in vivo system is likely so variable that it is impossible to decide if this motif has functional importance.(Mehra et al., 2020)

The majority of AD-causing mutations cluster at the interface between enzyme and substrate (as summarized in Figure 1), underpinning the idea that altered substrate binding and processing are fundamental to $\mathrm{fAD},($ Zhou et al., 2019) as also supported by consistent increase in the $\mathrm{A} \beta_{42} / \mathrm{A} \beta_{40}$ ratio,(Lemere et al., 1996; Murayama et al., 1999; Sun et al., 2016) and the fact that this ratio tends to correlate, despite the unavoidable noise in clinical data, with the clinical severity of the mutant.(Tang and Kepp, 2018) Recent crosslinking studies also support altered positioning of C99 as a consequence of FAD mutations in the $\gamma$-secretase catalytic subunit.(Trambauer et al., 2020) The structural model and the five mutations studied are summarized in Figure 1. 

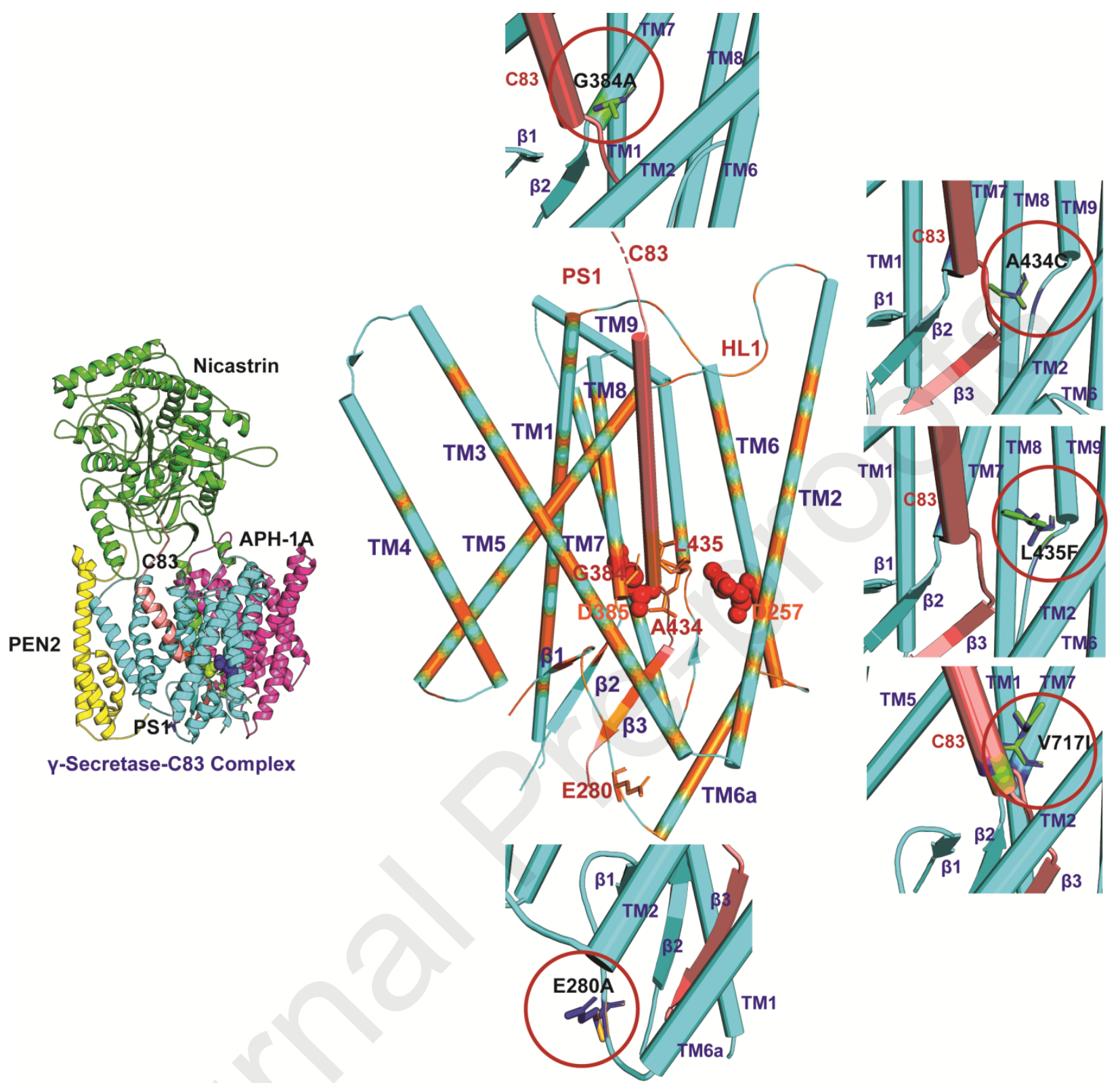

Figure 1. Studied models of APP-C83-bound $\gamma$-secretase. The left structure represents the wild type (6IYC)(Zhou et al., 2019). The central picture shows the distribution of pathogenic mutations in PS1 and APP-C83 (marked orange). The five pictures surrounding the central picture show the studied mutants, i.e. E280A close to TM6a, G384A in the GxGD motif, A434C and L435 of the PAL motif, and V717I beneath the TM domain of C83, with mutated sites marked as red circles. 


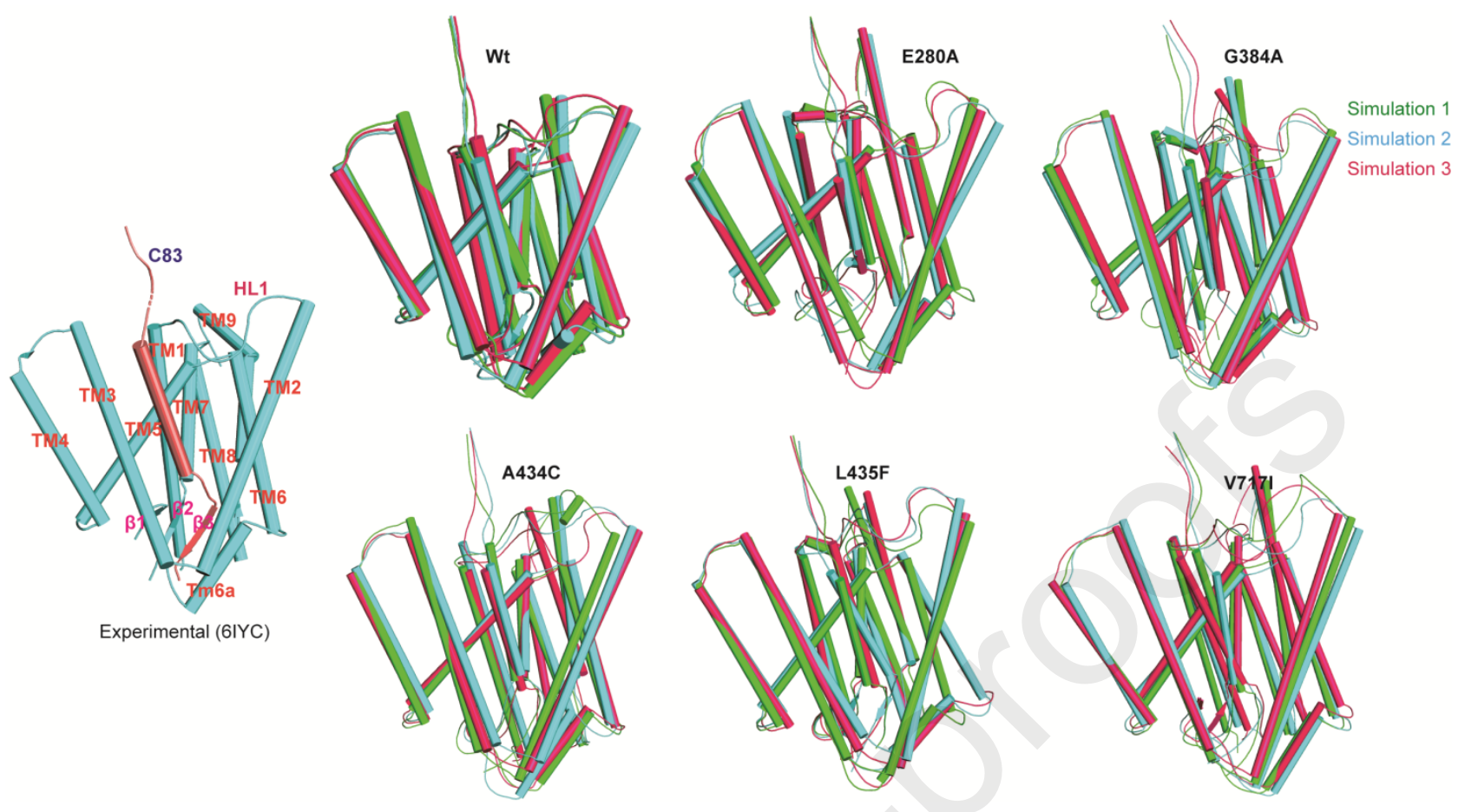

Figure 2. Structural arrangement of each TM domain (in PS1 and C83) and loops in simulated proteins compared to the experimental 6IYC structure. The average C $\alpha$-RMSD between 6IYC and the simulated structures were 1.17-1.66 $\AA$ for PS1 and 2.36-3.58 $\AA$ for the substrate (data summarized in Table S2).

The most ensemble-representative structure snapshots of each simulated trajectory displayed good structural convergence with average Ca RMSD of $2.06 \pm 0.39 \AA$ relative to the experimental structure 6IYC (Figure S1 and Table S2), i.e. with variations smaller than the experimental structural resolution. The global RMSD and topological arrangement of the TM domains are in essential agreement as expected, whereas the mobile loops in Nicastrin ECD and disordered cytosolic loops in PS1 differed due to the thermal motions that we explicitly simulated, which cannot be seen in the cryo-EM data.

Figure 2 shows the structural overlay of the experimental and computed structures of the catalytic subunit PS1 and the substrate C83 for each studied system. The average C $\alpha$-RMSD of 
PS1 was $\sim 1.36,1.24,1.31,1.66,1.17$, and $1.17 \AA$, respectively, for the WT, E280A, G384A, A434C, L435F, and V717I proteins, indicating very close similarity to the experimental structure of the backbone conformations, well-below the experimental resolution (6IYC solved at $2.60 \AA$ ). The main differences are noticed in HL1 and the local tilt of TM3, TM6, TM6a and TM9 in the mutants as compared to the WT (Figure 2).

Importantly, the average $\mathrm{C} \alpha-\mathrm{RMSD}$ of the substrate $\mathrm{C} 83$ was computed to $3.31,3.07,3.58$, 2.67, 2.36 and $3.17 \AA$, respectively, for the WT, E280A, G384A, A434C, L435F and V717I proteins, indicating much larger variability in the substrate fitting of the WT and mutant proteins. The RMSD of the substrate is on the high side as compared to the experimental C83, mainly because the bound C83 in 6IYC represents the PS1-cross-linked mutant, and the N-terminal region is flexible and contains some missing residues. We also expect that the experimental Asp-Ala mutation in the active site required to avoid substrate turnover(Zhou et al., 2019) will reduce the substrate binding and potentially increase flexibility in this area due to loss of a hydrogen bond, which is countered by the fixation by cysteine crosslinking.

\section{Membrane dynamics of substrate-bound $\gamma$-secretase mutants}

In order to also assess the realism of the membrane-protein system, which is not visible in the cryo data, the POPC bilayers were analyzed in detail (Figure S2). The order parameters and density profiles were in accordance with previously simulated(Jurkiewicz et al., 2012; Zhuang et al., 2016) and experimental lipid parameters.(Ferreira et al., 2013; Seelig and Waespe-Sarcevic, 1978)

The acyl order parameter $\left(\mathrm{S}_{\mathrm{CD}}\right)$ evaluates the structural orientation of the lipid tails with respect to the bilayer normal. Computed acyl order parameters for both chains were in good agreement with the experimental values(Ferreira et al., 2013) with a consistent trend both in the upper region close 
to water, a decrease at carbon 3 (in the sn 1 chain) and a major decrease at carbon-10 (in the sn2 chain), implying that our protein-membrane system is modeled accurately.

The RMSD as a function of simulation time (Figure S3) indicates that the backbone atoms showed similar behavior during the simulations with some minor exceptions as discussed below. The backbone RMSDs of the WT and mutants systems converged after $\sim 200 \mathrm{~ns}$ and displayed a constant trend in RMSD with an average RMSD of $\sim 0.3,0.28,0.29,0.29,0.26$ and $0.29 \mathrm{~nm}$, respectively, for the WT, E280A, G384A, A434C, L435F and V717I proteins, indicating that all systems reached stable conformation states during the last 300 ns that we used for collecting statistics throughout this work (Figure S3).

We extended our RMSD analysis to the individual subunits of $\gamma$-secretase (Figure S4). As expected, the Nicastrin (NCT) was very dynamic in all systems due to its mobile extracellular loop (NCT-ECD). This flexibility is characteristic of room temperature dynamics and thus not accessible by cryo-EM, but crucially allows NCT to act as a gatekeeper for potential substrates.(Bolduc et al., 2016a) In contrast to NCT-ECD, the dynamics of all the membraneembedded TM domains were relatively inflexible throughout the simulations. In all systems, during the initial 200-ns equilibration phase, the RMSD of the substrate C83 reached $\sim 0.2 \mathrm{~nm}$ and later displayed a constant stable trend until $500 \mathrm{~ns}$.

Radius-of-gyration plots showed that most of the $\gamma$-secretase proteins have similar $R_{g}$ values in close agreement with the experimental structure (average of $\sim 3.97 \mathrm{~nm}$ vs. $3.95 \mathrm{~nm}$ for 6IYC) (Figures S3 and S5). The SASA, which measures the total exposure of the protein to solvent, ranged from $598.7-618.5 \mathrm{~nm}^{2}$ (average of $\sim 606.3 \mathrm{~nm}^{2}$ vs. $606 \mathrm{~nm}^{2}$ for the experimental 6IYC structure), while in agreement with the experimental average, provides a large fluctuation range in solvent exposure not available from the cryo-EM data (Figure S3 and S5). These results, caused by the breathing mode of NCT, are in agreement with previous simulations of the wild- 
type protein.(Dehury et al., 2019c; Mehra et al., 2020) However, compared to the apo- $\gamma$-secretase protein,(Somavarapu and Kepp, 2017) the substrate-bound conformations are more compact. The dynamic stability statistics of all studied MD systems have been summarized in Table S3.

\section{Alzheimer-causing mutations produce more flexible ensembles}

We wanted to understand the structural fluctuations of the WT and mutant ensembles, as they may play a role in the pathogenic mechanism according to the FIST model.(Somavarapu and Kepp, 2017, 2016b; Tang et al., 2018) To this end, the RMSF values describing the C $\alpha$ atomic fluctuations were calculated for each simulated replica over the last $300 \mathrm{~ns}$ timescale of the MD trajectory and separated into individual amino acid sites for each subunit (Figure S6). Each trajectory experienced a similar pattern of fluctuation for each subunit. Notably, the NCT-ECD all cases displayed several very flexible regions whereas the single TM (Ser665-Phe698) displayed less flexibility. As expected, we observed major fluctuations in HL1 (Lys109-Glu123) potentially involved substrate gating,(Takagi-Niidome et al., 2015) and the disordered HL2 of PS1.

The segment Phe240-Glu245 of NCT-ECD interacts with the positively charged Lys699 of APP (near HL1 and TM1 of PS1) and may contribute to modulating the A $\beta$ length.(Petit et al., 2019; Szaruga et al., 2017) This site also binds some $\gamma$-secretase modulators, which may increase the stability of the $\gamma$-secretase-substrate complex thereby increasing the precision, retention time and trimming of the substrate towards shorter $A \beta$ mainly along the $A \beta_{40}$ pathway.(Tang et al., 2018) Our RMSF analysis of this region indicated major flexibility (Figure S7A) consistent with a modulatory effect of this type. To understand the flexibility in the catalytic site, we studied the fluctuations specifically for Asp257 and Asp385, Glu280, the GxGD motif and the PAL motif (Figure S7B). In most but not all cases fluctuations were larger than for WT in these regions. TM2, the C-terminal end of TM3, the extended helix from TM6 (TM6a) and TM9 displayed 
relatively more fluctuation than other transmembrane PS1 helices, in agreement with previous simulations.(Dehury et al., 2019c, 2019a; Somavarapu and Kepp, 2017)

As one of our main findings, the RMSF plots of the PS1 subunits (Figure 3A) indicated consistently higher residual fluctuations in the mutants $(0.12 \pm 0.04,0.11 \pm 0.027,0.12 \pm 0.04$, $0.11 \pm 0.02$, and $0.12 \pm 0.03 \mathrm{~nm}$ for E280A, G384A, A434C, L435F and V717I, respectively, averaged over the three replicates) compared to the WT $(0.07 \pm 0.02 \mathrm{~nm})$. In some replicates of E280A and L435F, we observed a distinct flexibility of PEN2, and the substrate C83 was more flexible in the mutants compared to the WT ensembles (Figure 3B). Studies have previously indicated major conformational flexibility of the substrate TM as a critical feature.(Götz et al., 2019; Pester et al., 2013) The Val717 residue (positioned at the wounded region next to the substrate TM) was also more mobile in the mutant vs. wild type (Figure S8). Figure S8 summarizes these average RMSFs in a simple way for the WT and mutant ensembles.

\section{Global membrane dynamics of $\gamma$-secretase-substrate holoenzymes}

We also analyzed the overall essential dynamics of the full systems via PCA. In this analysis, the principal components (PCs) define the concerted atomic displacements of the ensembles.(Amadei et al., 1993) The most significant collective motions were emphasized by the top-three PCs (PC1, PC2 and PC3, Figures S9-S16; statistics summarized in Table S4). The first three PCs accounted for $\sim 60 \%$ of all motions. In the simulations, at least one replicate occupies a larger conformational space mostly driven by the concerted movement of the NCT ECD, the intracellular region of PEN2 and APH1-A (Figures S11-S16), consistent with many previous MD studies.(Aguayo-Ortiz et al., 2017; Dehury et al., 2019c; Hitzenberger and Zacharias, 2019; Somavarapu and Kepp, 2017) The juxta-membrane region of PEN2, which act an exosite for substrate recruitment also displayed out-wards movement (Figures S11-S16). 
A

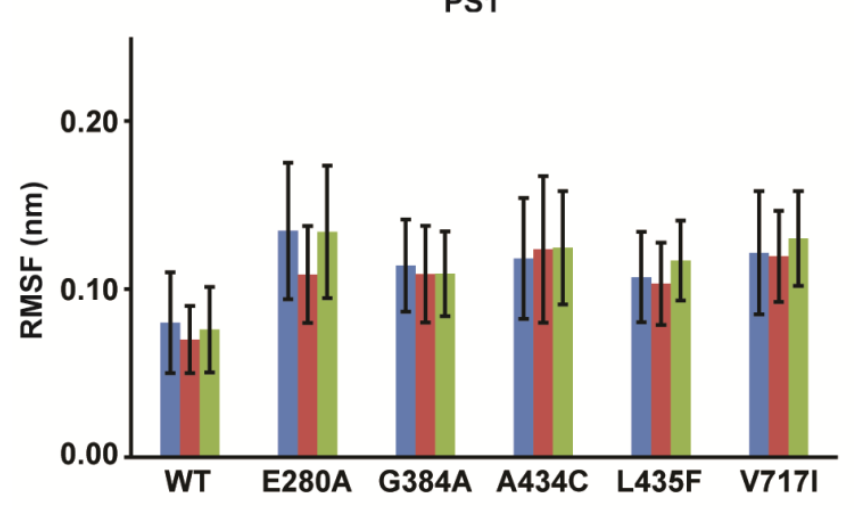

B

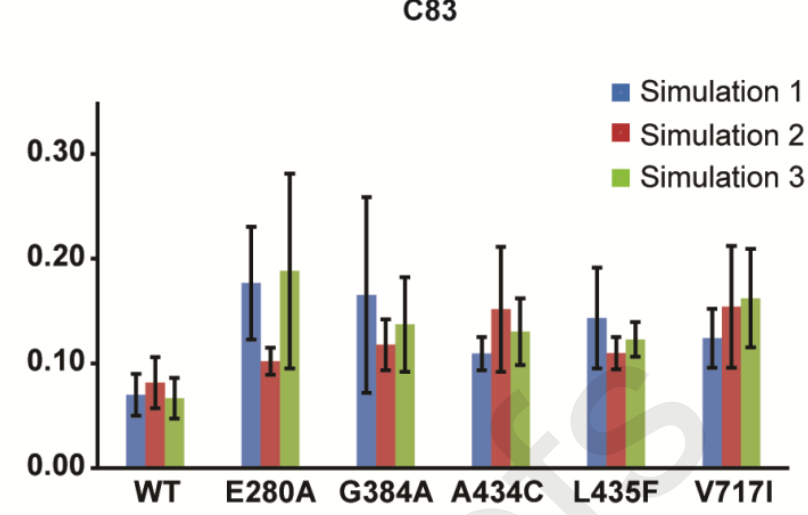

Figure 3. The degree of flexibility measured by the Ca-RMSF of catalytic PS1 and the substrate C83 of $\gamma$-secretase-complex systems during the equilibrium phase (last $300 \mathrm{ns)}$ of MD. More flexibility is seen consistently in the mutants as compared to wild type.

Bai et al.(Bai et al., 2015a) previously used the PEN2 and PS1 tilting angles to group the cryo-EM structures into three different structural classes. The same tilting motions can also be applied to the catalytic PS1 and APH-1A subunits. We aligned the most representative structure from each simulation (obtained from cluster analysis) with the experimental 6IYC, which are in good agreement (average $\sim 2.05 \AA$ ) as shown in Figure 4. Figures 4A and 4B depict representative snapshots (marked in blue), highlighting the sampled protein conformations relative to 6IYC. We observe that the TM of C83 moved $\sim 1.2 \AA$ from its initial position most likely due to the experimental cysteine and alanine mutations being equilibrated in our wild type model. We note that the three mutants E280A, G384A and V717I displayed slightly higher tilting of C83. For the mutants, the TM2, TM3 and TM6a, TM7 and TM9 of PS1 typically exhibited more structural variation, in accordance with the RMSD and RMSF analysis discussed above. 
A
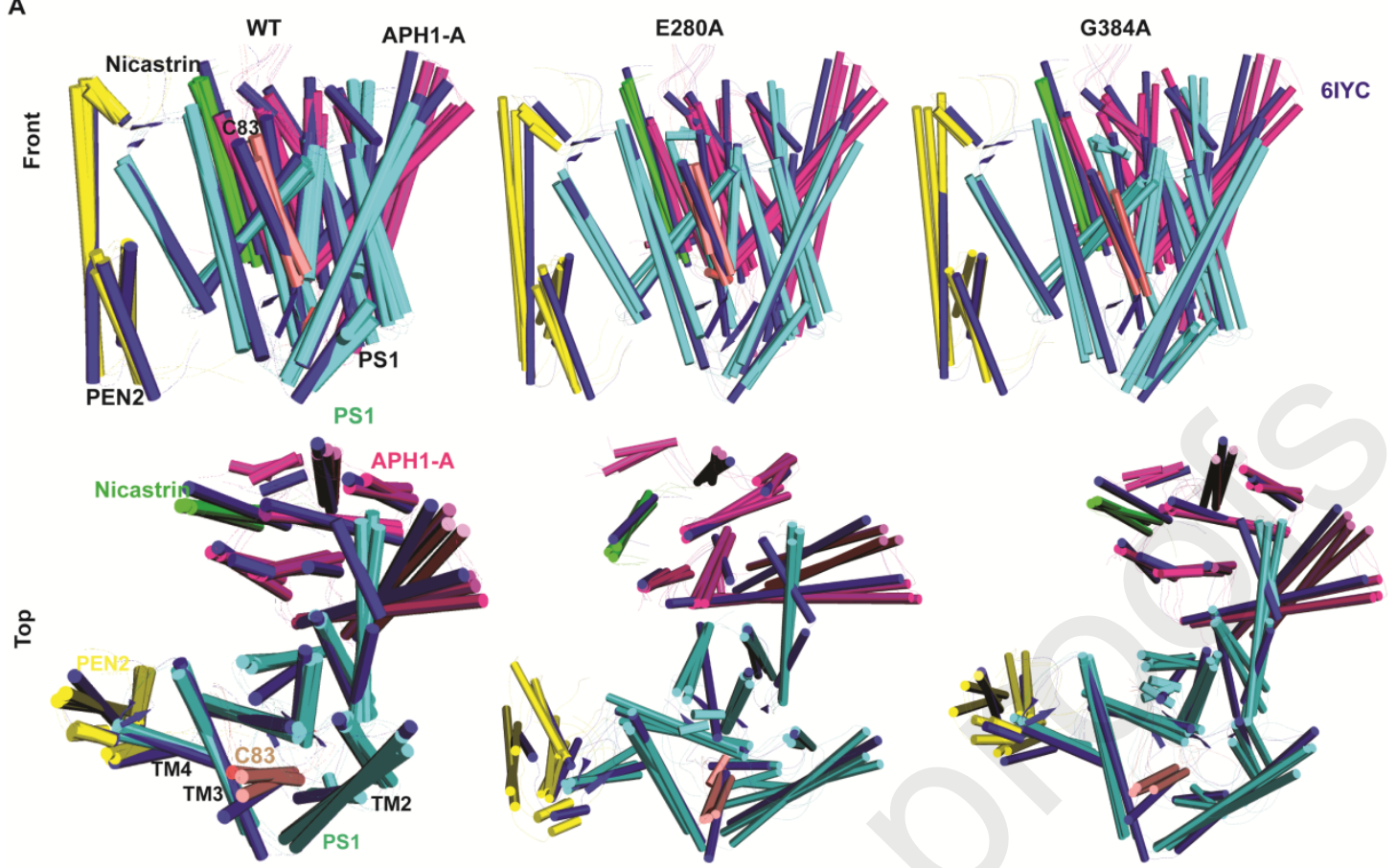

B
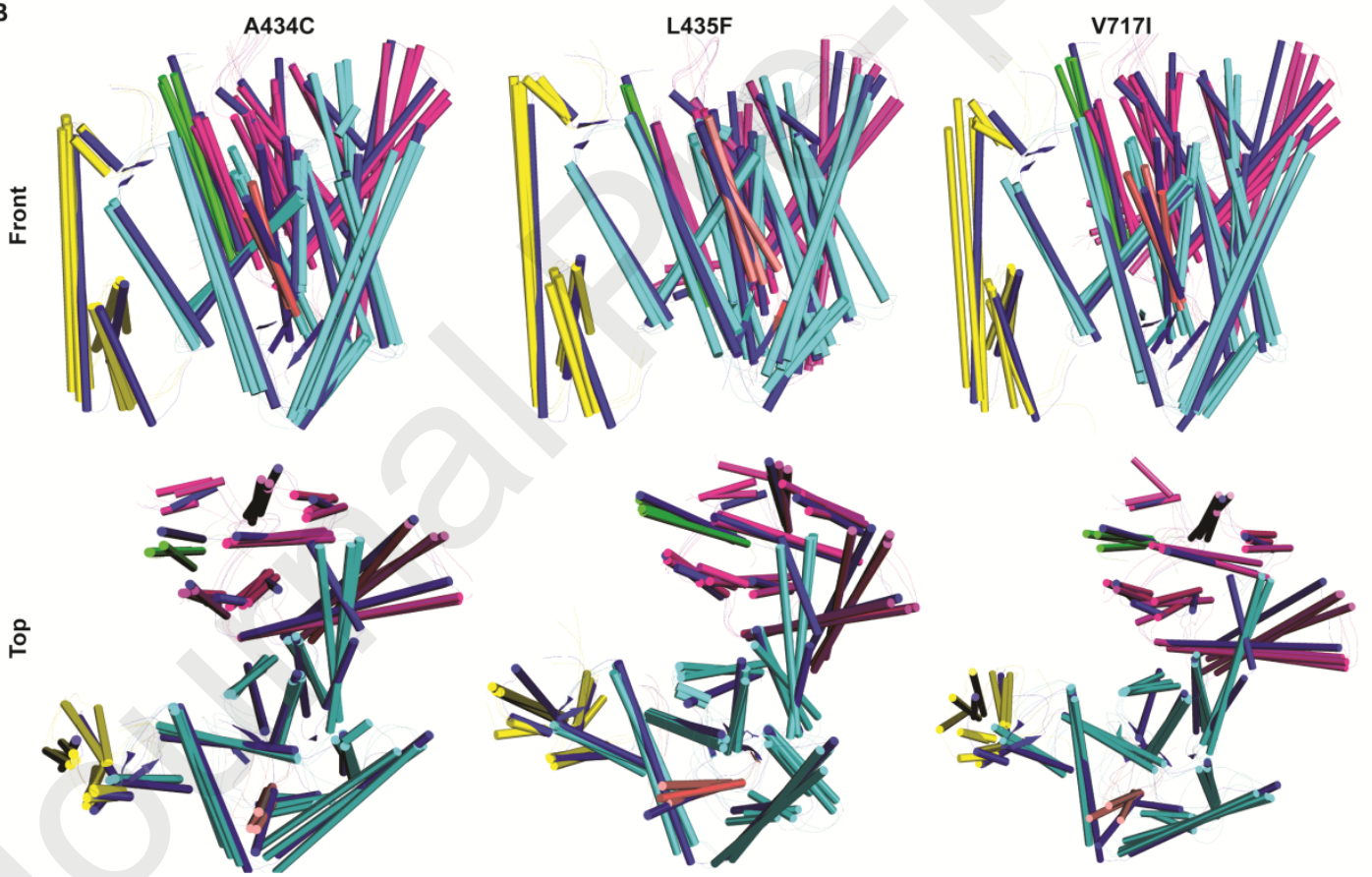

Figure 4. TM domains of simulated substrate-bound $\gamma$-secretase WT and mutants compared

to the experimental 6IYC structure. (A) Snapshots showing the front and top view of the simulated WT, E280A and G384A. (B) Snapshots displaying the front and top view of A434C, L435F and V717I. The structures were aligned using the C $\alpha$-atom pairs (Nicastrin: green, PS1: cyan, APH1-A: magenta, yellow: PEN2 and salmon: C83. 6IYC is colored in blue). 


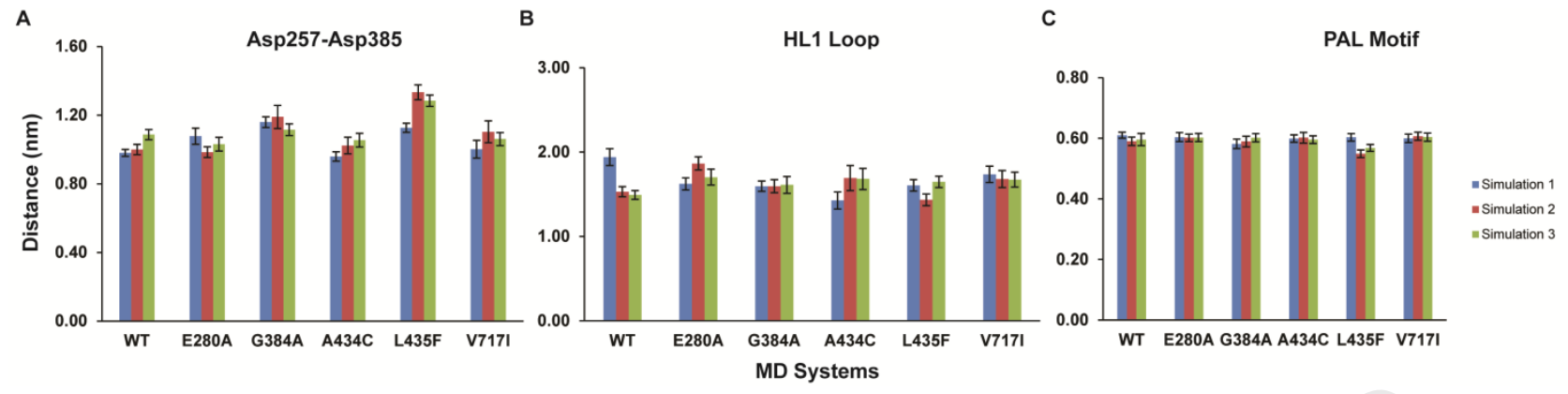

Figure 5. The average $\mathrm{C} \alpha-\mathrm{C} \alpha$ distances of the catalytic Asp257-Asp385 pair, the terminal residues of the HL1 loop and the PAL motif. (A) Distance between the catalytic pairs during the last 300 ns MD. (B) The distance mediated by the terminal residues of HL1. (C) Size of the PAL motif (end-to-end distance of $\mathrm{C} \alpha$ atoms) during the last 300 ns of simulation.

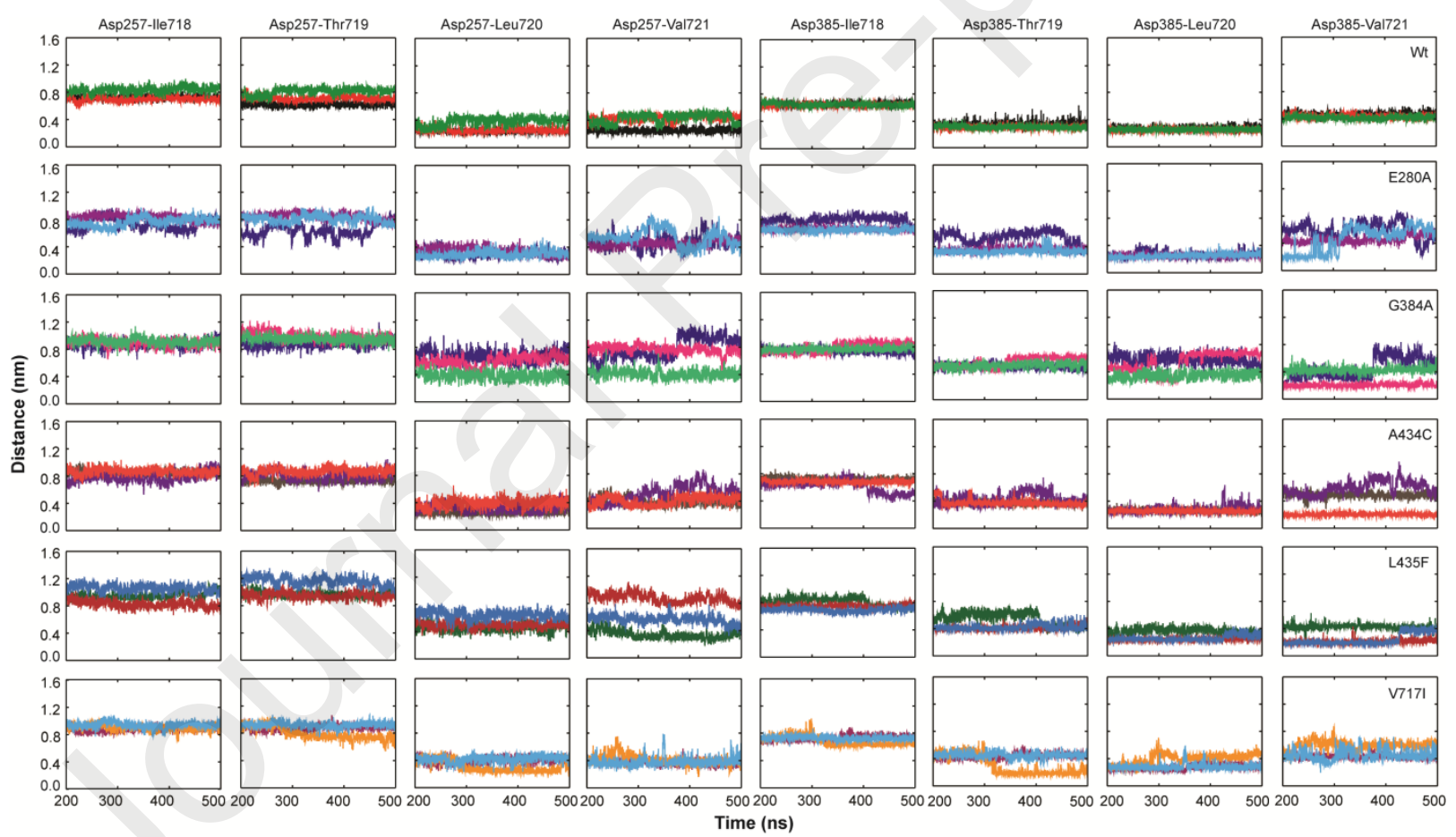

Figure 6. Time-resolved distance from catalytic Asp257 and Asp385 to \&-cleavage sites at Thr719-Leu720 (yielding $\mathbf{A} \boldsymbol{\beta}_{48}$ ) or at Leu720-Val721 (yielding $\mathbf{A} \boldsymbol{\beta}_{49}$ ). Substantial variation in several mutant ensembles relative to WT is suggested to be the molecular cause of imprecise $\gamma$ secretase cleavage. 


\section{Some mutants produce distinctly wider active sites}

Recent studies have reported distinct conformational states of the catalytic active site, which can at least partly be described by the Asp257-Asp385 distance as a measure of the size of the active site.(Aguayo-Ortiz et al., 2017; Bai et al., 2015a; Somavarapu and Kepp, 2017) The average Asp257-Asp385 ( $\mathrm{C} \alpha-\mathrm{C} \alpha)$ distance was computed from our ensembles to be 1.02, 1.03, 1.15, 1.01, $1.25,1.05 \mathrm{~nm}$ for the WT, E280A, G384A, A434C and L435F systems (experimental 6IYC $=1.06$ nm). Consistent with our previous findings and the FIST model, the distances fall in two groups representing a smaller, more compact active site (the semi-open conformation; $1.01-1.05 \mathrm{~nm}$ ) and a larger, more variable active site (the open conformation, 1.15-1.25 nm) (Figure 5A). We note that G384A and L435F featured particularly open states compared to the other systems, i.e. these mutants shift the main conformation of the protein ensemble from semi-open to open, whereas other mutants do so to a smaller extent. For comparison, the $\mathrm{C} \alpha-\mathrm{C} \alpha$ distance between end-residues of the substrate gating HL1 (measuring the size of this loop's in terms of its anchor points and the substrate recruitment PAL motif did not show any notable differences between mutants and WT (Figures 5B and 5C).

In addition to the $\mathrm{C} \alpha-\mathrm{C} \alpha$ distances, we also measured the minimum atomic distances during the last 300 ns for these three motifs (Figure S17A-S17C). These are represented by the side-chain interaction and thus much more variable, implying that the side chains can easily adjust in the more important space defined by the $\mathrm{C} \alpha-\mathrm{C} \alpha$ distance, which defines the two conformation states of the active site caused by relative PS1 TM motions.

Analysis of the MD snapshots at different time intervals and for the ensemblerepresentative structures shows water entering the active site from the intracellular side and forming hydrogen bonds with the catalytic aspartates (Figure S18). Such hydrogen bonds with the catalytic Asp385/Asp257 may activate water for nucleophilic attack on the carbonyl of the peptide 
bonds of the substrate. In addition, the residues of the GxGD and PAL motifs also form several hydrogen bonds with water molecules. These observations agree well with a previous MD study (Bhattarai et al., 2020).

\section{Most mutations increase substrate cleavage site dynamics}

To understand the dynamics between the catalytic aspartates and the cleavage sites of C83, we also measured the distance between these residues (Figure 6). Thr719-Leu720 or Leu720-Val721 define $\varepsilon$-cleavage sites of the substrate during trimming to produce $A \beta$ either via the $A \beta 48$ or A $\beta 49$ pathway.(Steiner et al., 2018) In mutants, the distance between the catalytic residues and these cleavage sites differed in some cases considerably from those of the WT (Figure 6). The distance between Asp257 and Thr719-Leu720 or Leu720-Val721 and Asp385 and Leu720-Val721 were quite variable. We propose that the large thermal variation in the distance is the direct structural-dynamic reason for the imprecise cleavage that enables two types of trimming pathways to occur in $\gamma$-secretase, while at the same time causing earlier release of relatively longer $\mathrm{A} \beta$ peptides (i.e. higher $A \beta_{42} / A \beta_{40}$ ratio). This interpretation fits well both with the seminal experimental studies(Szaruga et al., 2017) and the theoretical FIST model.(Somavarapu and Kepp, 2017, 2016b; Tang et al., 2018) The destabilizing effects that these mutations exert on PS1 translate into lower $\gamma$-secretase activity.(Szaruga et al., 2015; Veugelen et al., 2016)

\section{TM helix dynamics in the membrane at physiological temperature}

Since the relative motions of the PS1 TM helices are ultimately responsible for moving the backbone $\mathrm{C} \alpha$ atoms and thus controlling the active site size, we analyzed the helical properties of the simulated ensembles in more detail (Figure 7 and S19). The average helical length of all TM domains remained the same, but we observed a loss of helical tendency in TM3, TM4 and TM9 in 
PS1, which is apparently mainly an effect on interaction with the lipid bilayer at room temperature, and thus not obtainable from the experimental cryo-EM data. None of the helix tendencies are significantly different for the WT and mutants, indicating that they are not a source of pathogenicity, as we propose are the case for the active site size discussed above.

In all systems, the C-terminal end of the TM1 helix lost some of its helical conformation, indicating that this is a persistent feature of the dynamics regardless of the WT/mutant system. A $\beta_{42}$-lowering $\gamma$-secretase modulators commonly target TM1 of PS1, thereby affecting the structure of the site.(Ohki et al., 2014) Similarly, TM1 can exhibit a piston-like vertical motion affecting $\gamma$-secretase activity and modulate the A $\beta$ production.(Cai et al., 2017) TM1 lies near the catalytic GxGD and PAL motifs with its C-terminal fragment facing the catalytic site. Recent competitive inhibition assays indicate that binding of inhibitors affects the water accessibility at the membrane border of TM1.(Takagi et al., 2010) We note that C83 also displayed loss of helicity in agreement with the experimental cryo-EM structure, a feature argued to expose the peptide bonds of the substrate to nucleophilic attack by the catalytic water.(Zhou et al., 2019)

The PAL motif and the extracellular portion of TM9 are highly water accessible and located in proximity to the catalytic site and may also contribute to substrate processing.(Sato et al., 2008) From our ensembles, we observe a loosening of the helical TM at the luminal end TM9 (Figure 7) with an alpha-helix-like structure that extends along the interface between the membrane and the extracellular solvent, which could perhaps be of importance to the substrate entry into $\gamma$-secretase, although this remains speculative as we did not study the actual substrate docking process, which would require prohibitively long simulation time scales. 


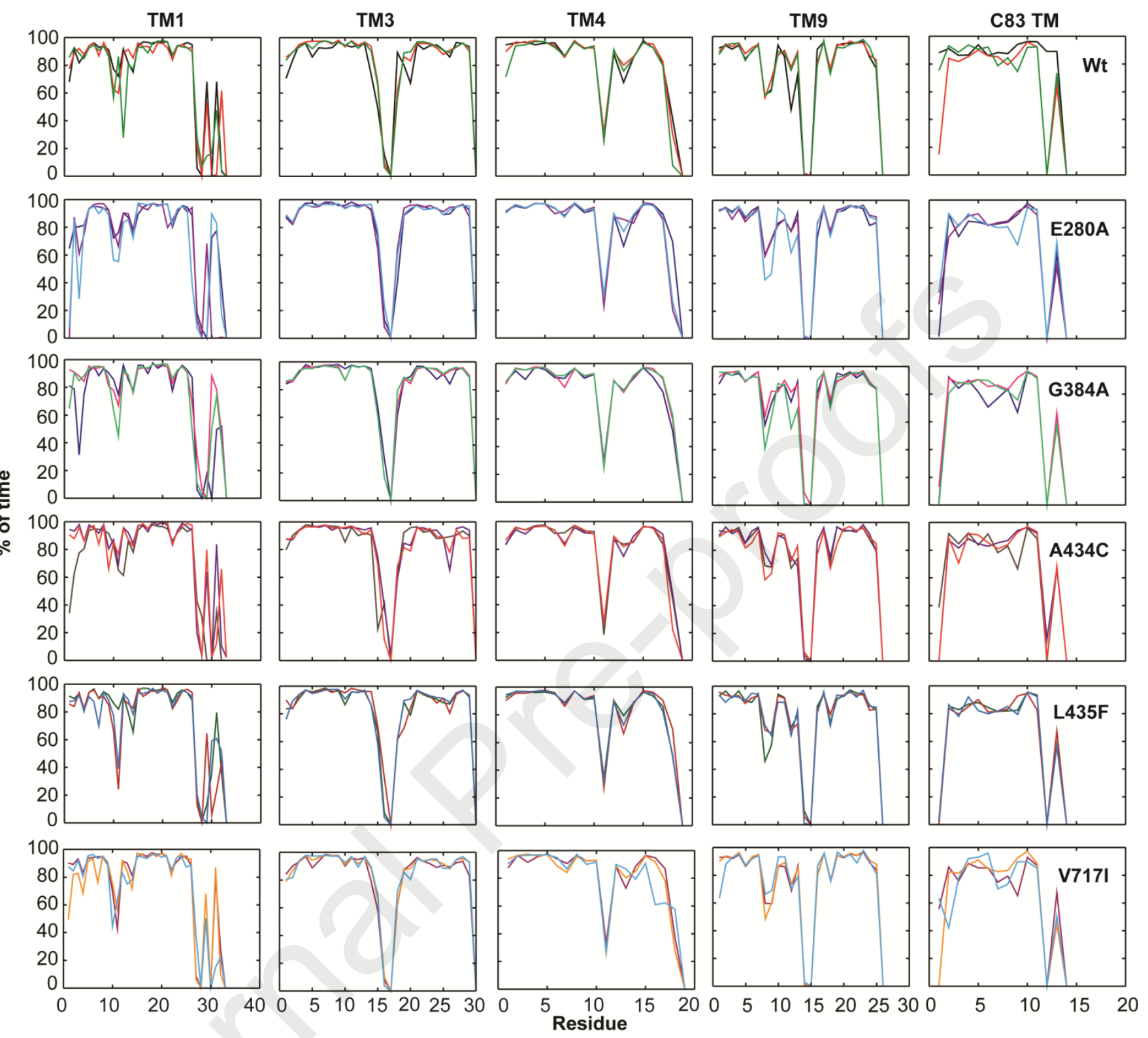

Figure 7. Simulated helix tendencies of the some key TM domains of PS1 and C83 in POPC

lipid bilayers. TM3, TM4 and TM9 of PS1 tend to lose some helicity in the lipid bilayer at room temperature, indicating plasticity of these TM helices. 
Journal Pre-proofs

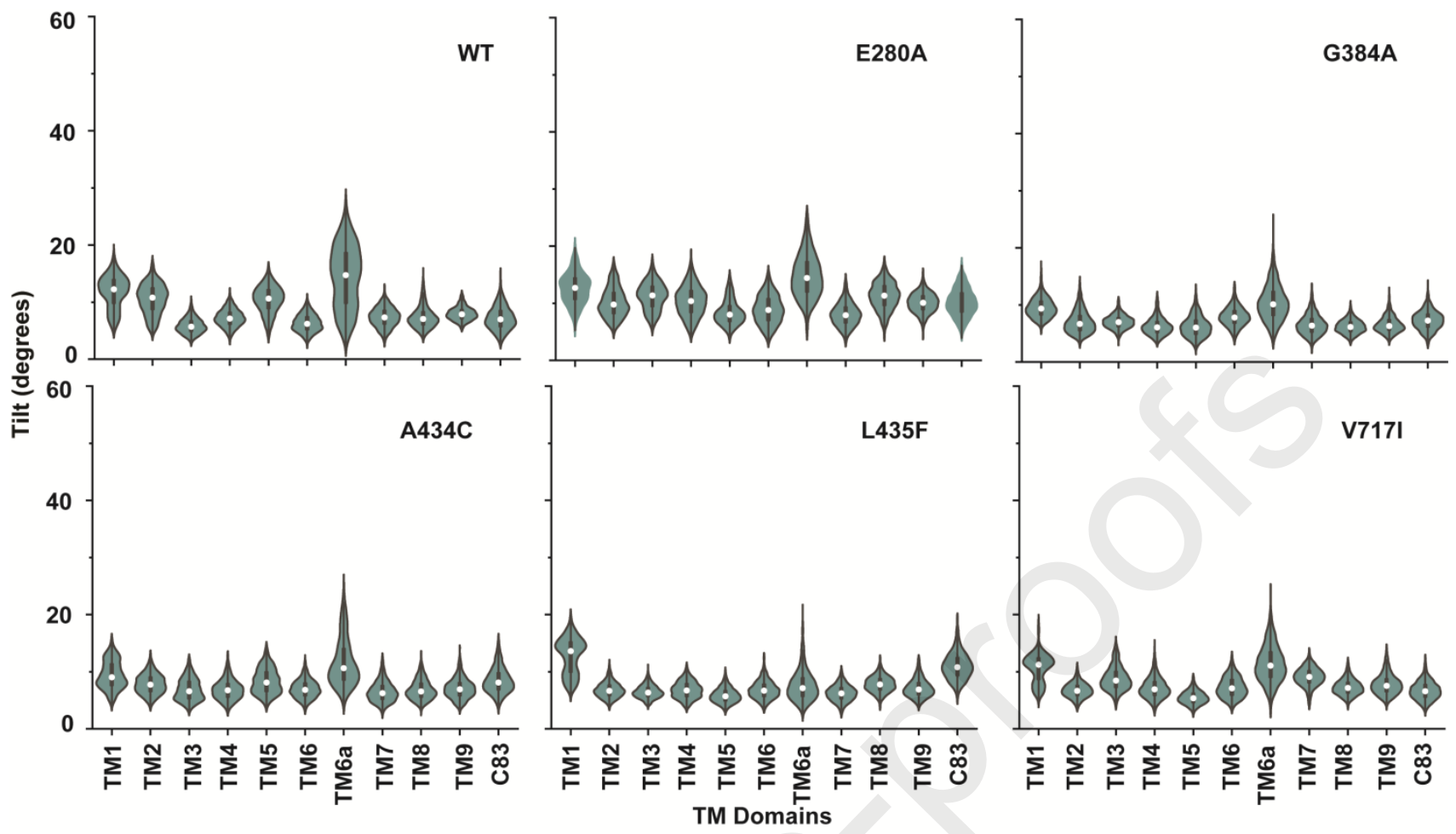

Figure 8. Violin plots depicting the average tilt angles of TM domains of PS1 and the substrate C83 in simulation 3 of each of the six studied systems. The white dot inside the violin plot depicts the median tilt angle (in degrees).

We also computed the tilt angles of the RMs as a possible molecular basis for the open and semi-open conformation states (Figure 8 and S20). Several of these RMs are involved in substrate binding due to the horseshoe shape of the PS1 structure.(Li et al., 2017) The average tilt angle distributions of PS1 and C83 are summarized in Table S5. We observed a characteristic tendency towards slightly broader and less dynamic tilt angles in the mutants for TM1, TM2, TM5, TM6a and TM9 as compared to wild type. TM6a displayed the most notable differences, and a large distribution particularly in the WT, i.e. the mutations tend to restrict the TM6a movement. As summarized in Table S6, the mutants commonly display more variable hydrogen bond networks

26 
than the WT protein, and several mutations disrupt hydrogen bonding between PS1 and the substrate, consistent with the looser substrate binding dynamics discussed above.

To better understand how the fAD mutations affect the secondary structure, we computed the time evolution of the secondary structure of PS1 and C83 using DSSP (Figures S21). We commonly observed complete loss of the $\beta$-strands of PS1 or C83, although some simulations retained a small strand extending from TM6a (Figures S22-S25). This confirms previous side-byside comparisons of the cryo-EM and simulated cold and hot states indicating that the sheet is not stable at room temperature due to thermal unzipping, which is a common feature of short secondary structure elements.(Mehra et al., 2020) The significance of the sheet recognition motif in the cryo data may thus have been somewhat overstated, as also supported by the fact that the segment is hard to identify even with some computational tools directly on the cryo coordinates. Thus, we cannot assign significance to this motif until supported by other data at room temperature.

To understand how the fAD mutations affect the intermolecular contacts between the catalytic PS1 and the substrate, we computed residue pairs forming hydrogen bonds and electrostatic contacts (Table S7). As evident from this analysis, most of the fAD mutants tend to lose important non-bonded contacts as compared to the wildtype. For instance, the densely populated hydrogen-bonding network and electrostatic contacts within the catalytic pocket around GxGD motif become perturbed upon mutation of glycine to alanine at position 384 . Similarly, the L435F mutation results in loss of hydrogen bonding between the PAL motif and substrate C83. Remarkably, V717I shifted the substrate away from the $\varepsilon$ cleavage site.

The mutant G384A showed particularly large effects compared to WT in our study. This site is located in the GxGD motif(Pérez-Revuelta et al., 2010; Steiner et al., 2000) which is central to substrate cleavage.(Kretner et al., 2013; Yamasaki et al., 2006) Substrates not meeting the steric 
requirements will not be cleaved properly by the enzyme, producing potential "sloppy" cleavage along both cleavage pathways. At the same time, G384A substantially increases the $A \beta_{42} / A \beta_{40}$ ratio as most other PS1 mutations.(Sun et al., 2016) Close inspection at the interface of experimental 6IYC structure indicates a hydrogen bond between the amide group of Gly384 of PS1 and the carbonyl oxygen of Thr719 of APP-C83. Looking at the snapshots of G384A obtained from our simulations, we observed that this fold is completely altered due to the substitution to Alanine, causing loss of these hydrogen bonds (Figure S26 and Table S7).

Val717 of APP (located near the $\gamma$-secretase cleavage site) is positioned in a narrow hydrophobic pocket formed by three residues Phe237, Ile387, and Phe388 of PS1. Several lines of evidence suggest that V717I increases the $A \beta_{42} / A \beta_{40}$ ratio by increasing $A \beta_{42}$ levels with little effect on $A \beta_{40}$ levels.(De Jonghe et al., 2001; Eckman et al., 1997; Herl et al., 2009; Theuns et al., 2006) We found that the C-terminal half of the substrate TM helix formed van der Waals contacts with PS1, notably between Ile718 of the substrate and Met146, Thr147, and Leu268 of PS1, whereas Leu720 interacted with Ala434, Leu435, and Gly384 of the PAL and GxGD motifs. We notably found that the mutation affected the tilt of the substrate helix (Figure S27).

$\gamma$-secretase harbors conserved YD (TM6) and GLGD (TM7) motifs in the catalytic site along with the PAL motif at the N-terminal end of TM9. The GLGD and PAL motifs are highly conserved in related aspartyl proteases.(Moliaka et al., 2004) The PAL motif is critical for $\gamma$ secretase activity, as shown from the binding of the transition state analog L-685 (Wang et al., 2006) and important for the recognition of C99.(Sato et al., 2008; Zhou et al., 2019) Substitutions of either P433 or A434 with small residues (i.e. Ala, Gly, or Ser) preserve $\gamma$-secretase activity, whereas bulky amino acids (i.e. Val, Leu, or Ile) abolish activity.(Wang et al., 2006)

To understand the mechanistic basis of altered C83 binding by $\gamma$-secretase caused by the A434C mutant, we compared the experimental 6IYC and the mutant MD ensembles (Figure S28). 
In some of our simulations, the A434C mutant causes a partial shift at Leu720 and Val721 of the substrate C83 in the $\varepsilon$-cleavage site, and loses the hydrogen bond between Leu432 of PS1 and Met722 of C83. Although these changes at the initial $\varepsilon$-cleavage sites are qualitative indications, not necessarily dominant aspects of the ensembles, they seem consistent with an experimentally observed effect on the trimming pathways leading to A $\beta$.(Morishima-Kawashima, 2014)

Similarly, the L435F variant affecting the PAL motif can generate pathogenic $A \beta_{43}$ species.(Kretner et al., 2016) As compared to apo- $\gamma$-secretase, the PAL motif in the substratebound (6IYC) structure moves towards the substrate, and Leu432 interacts with C 83 via hydrogen bonds. The mutant L435F altered the local conformation of PS1 around the substrate and lost hydrogen bonds in two of our simulations (Figure S29). This suggests that this fAD mutant primarily affects the positioning of the substrate cleavage region leading to increased relative levels of longer $A \beta_{43}$ or $A \beta_{42}$.

In summary, our simulations show consistent changes in substrate positioning caused by all the PS1 fAD mutants, which we assume provides a structural basis for some of the data observed in assays of the mutants. Specifically, we conclude that the substrate positioning will change the preference between the trimming pathways $A \beta_{49 / 46 / 43}$ or $A \beta_{48 / 45 / 42}$ whereas impaired overall binding affinity relative to the wild type will cause an overall loos of activity (and thus earlier release of longer products) along both pathways. PS1 fAD mutations have previously been shown to weaken the binding of $A \beta_{42}$ and reduce the activity of $\gamma$-secretase for-as measured by $\mathrm{A} \beta_{38 .}$.(Okochi et al., 2013) These conclusions are broadly in line with the FIST model of the $\gamma$-secretase structure-function relationship. 


\section{Conclusions}

We have explored the membrane dynamics at physiological temperature of five FAD-causing mutants of substrate-bound $\gamma$-secretase (four PS1 and one APP mutation). Our results show that pathogenic mutation increase the conformational flexibility of the substrate binding site, which is in accordance with the FIST model and earlier experimental studies of mutant effects on substrate cleavage.(Szaruga et al., 2017)

We believe the active and inactive states of importance to the observed $A \beta$ assays are defined by open and semi-open states due to the Asp-Asp distance governed by PS1 TM movements (the FIST mechanism), which is long (> $10 \AA$ ) consistent with the xryo-EM data. The timescale of these helix movements are well-sampled as shown in many previous studies, giving broad tilt angle distributions with very many visits, but all of course occurring on the experimental structural background.(Dehury et al., 2019c, 2019a; Mehra et al., 2020; Somavarapu and Kepp, 2017) We cannot sample out of this experimental background: The large loop motions and actual substrate docking are much slower than MD can afford. The catalytic step itself may occur on a timescale of minutes or even hours,(Kamp et al., 2015) much slower than any MD can describe for many years to come. Hypothesized active MD states will be very transient compared to the slow, rate limiting step of peptide bond hydrolysis, which is not proton transfer but the breaking of the covalent peptide bonds. Thus, any views on transient active states in relation to MD sampling are speculative, and we favor studying perturbations around the dominating ensemble as seen in the cryo-EM data. Thus, we believe we are studying the mutant effects in the best possible way, but welcome other views on this important matter with open eyes.

In two of the pathogenic mutations G384A (belonging to the important GxGD motif) and L435F (of the PAL motif) we observed a particularly large ensemble-averaged Asp-Asp distance, indicating that the two mutants favor open conformation states, which we argue lead to less stable 
and more variable binding, imprecise cleavage, and release of relatively longer A $\beta$ products. Our results also highlight how mutations affect the dynamics of the distance between catalytic site and the cleavage site specific residues involved in the two of the cleavage pathways i.e., Leu49-Val50 and Thr48-Leu49. The large thermal variation in these distances may be a direct structuraldynamic reason for the imprecise cleavage that enables two types of trimming pathways in $\gamma$ secretase. The more open and dynamic state produces less precise cleavage along both pathways and a tendency towards earlier release of the products, giving diverse, and somewhat longer A $\beta$ peptides. This mechanism, we propose, underlies the molecular function of fAD mutations, and should thus be specifically targeted in future therapeutic strategies.

\section{Acknowledgements}

The authors acknowledge computer time from DTU high-performance computing facility, Lyngby, DTU. The Novo Nordisk Foundation, grant NNF17OC0028860, is gratefully acknowledged for supporting this work.

\section{Competing Interests statement}

All authors hereby declare that they have no competing interests, neither financial nor nonfinancial, related to this work.

\section{Supporting Information}

The supporting information includes additional information to replicate and scrutinize the computational work. 


\section{References}

Abraham, M.J., Murtola, T., Schulz, R., Páll, S., Smith, J.C., Hess, B., Lindah, E., 2015. Gromacs: High performance molecular simulations through multi-level parallelism from laptops to supercomputers. SoftwareX 1-2, 19-25. https://doi.org/10.1016/j.softx.2015.06.001

Aguayo-Ortiz, R., Chávez-García, C., Straub, J.E., Dominguez, L., 2017. Characterizing the structural ensemble of $\gamma$-secretase using a multiscale molecular dynamics approach. Chem. Sci. 8, 5576-5584. https://doi.org/10.1039/c7sc00980a

Aguayo-Ortiz, R., Dominguez, L., 2018. Simulating the $\gamma$-secretase enzyme: Recent advances and future directions. Biochimie 147, 130-135. https://doi.org/10.1016/j.biochi.2018.01.007

Aguayo-Ortiz, R., Guzmán-Ocampo, D.C., Dominguez, L., 2019. Toward the Characterization of DAPT Interactions with $\gamma$-Secretase. ChemMedChem 14, 1005-1010. https://doi.org/10.1002/cmdc.201900106

Amadei, A., Linssen, A.B.M., Berendsen, H.J.C., 1993. Essential dynamics of proteins. Proteins Struct. Funct. Bioinforma. 17, 412-425.

Bai, X., Rajendra, E., Yang, G., Shi, Y., Scheres, S.H., 2015a. Sampling the conformational space of the catalytic subunit of human $\gamma$-secretase. Elife 4, 551-560. https://doi.org/10.7554/eLife.11182

Bai, X., Yan, C., Yang, G., Lu, P., Sun, L., Zhou, R., Scheres, S.H.W., Shi, Y., 2015b. An atomic structure of human $\gamma$-secretase. Nature 525, 212-218. https://doi.org/10.1038/nature14892

Baldwin, R.L., 1996. How Hofmeister ion interactions affect protein stability. Biophys. J. 71, 2056-2063. https://doi.org/10.1016/S0006-3495(96)79404-3

Ballard, C., Gauthier, S., Corbett, A., Brayne, C., Aarsland, D., Jones, E., 2011. Alzheimer's disease. Lancet 377, 1019-1031. https://doi.org/10.1016/S0140-6736(10)61349-9 
Bauduin, P., Renoncourt, A., Touraud, D., Kunz, W., Ninham, B.W., 2004. Hofmeister effect on enzymatic catalysis and colloidal structures. Curr. Opin. Colloid Interface Sci. 9, 43-47. https://doi.org/10.1016/j.cocis.2004.05.031

Beel, A.J., Sanders, C.R., 2008. Substrate specificity of $\gamma$-secretase and other intramembrane proteases. Cell. Mol. life Sci. 65, 1311-1334.

Bentahir, M., Nyabi, O., Verhamme, J., Tolia, A., Horre, K., Wiltfang, J., Esselmann, H., De Strooper, B., 2006. Presenilin clinical mutations can affect gamma-secretase activity by different mechanisms. J. Neurochem. 96, 732-742. https://doi.org/10.1111/j.14714159.2005.03578.x

Berezovska, O., Lleo, A., Herl, L.D., Frosch, M.P., Stern, E. a, Bacskai, B.J., Hyman, B.T., 2005. Familial Alzheimer's disease presenilin 1 mutations cause alterations in the conformation of presenilin and interactions with amyloid precursor protein. J. Neurosci. 25, 3009-3017. https://doi.org/10.1523/JNEUROSCI.0364-05.2005

Bhattarai, A., Devkota, S., Bhattarai, S., Wolfe, M.S., Miao, Y., 2020. Mechanisms of $\gamma$-Secretase Activation and Substrate Processing. ACS Cent. Sci. 6, 969-983. https://doi.org/10.1021/acscentsci.0c00296

Bolduc, D.M., Montagna, D.R., Gu, Y., Selkoe, D.J., Wolfe, M.S., 2016a. Nicastrin functions to sterically hinder $\gamma$-secretase-substrate interactions driven by substrate transmembrane domain. Proc. Natl. Acad. Sci. 113, E509-E518.

Bolduc, D.M., Montagna, D.R., Seghers, M.C., Wolfe, M.S., Selkoe, D.J., 2016b. The amyloidbeta forming tripeptide cleavage mechanism of $\gamma$-secretase. Elife 5, e17578.

Borchelt, D.R., Thinakaran, G., Eckman, C.B., Lee, M.K., Davenport, F., Ratovitsky, T., Prada, C.-M., Kim, G., Seekins, S., Yager, D., Slunt, H.H., Wang, R., Seeger, M., Levey, A.I., Gandy, S.E., Copeland, N.G., Jenkins, N.A., Price, D.L., Younkin, S.G., Sisodia, S.S., 1996. 
Familial Alzheimer's Disease-Linked Presenilin 1 Variants Elevate A $\beta 1-42 / 1-40$ Ratio In

Vitro and In Vivo. Neuron 17, 1005-1013. https://doi.org/10.1016/S0896-6273(00)80230-5

Brouwers, N., Sleegers, K., Van Broeckhoven, C., 2008. Molecular genetics of Alzheimer's

disease: an update. Ann. Med. 40, 562-583. https://doi.org/10.1080/07853890802186905

Buchoux, S., 2017. FATSLiM: A fast and robust software to analyze MD simulations of

membranes. Bioinformatics 33, 133-134. https://doi.org/10.1093/bioinformatics/btw563

Cai, T., Yonaga, M., Tomita, T., 2017. Activation of $\gamma$-secretase trimming activity by topological changes of transmembrane domain 1 of presenilin 1. J. Neurosci. 37, 12272-12280. https://doi.org/10.1523/JNEUROSCI.1628-17.2017

Campion, D., Dumanchin, C., Hannequin, D., Dubois, B., Belliard, S., Puel, M., ThomasAnterion, C., Michon, A., Martin, C., Charbonnier, F., Raux, G., Camuzat, A., Penet, C., Mesnage, V., Martinez, M., Clerget-Darpoux, F., Brice, A., Frebourg, T., 1999. Early-onset autosomal dominant Alzheimer disease: prevalence, genetic heterogeneity, and mutation spectrum. Am. J. Hum. Genet. 65, 664-670. https://doi.org/10.1086/302553

Cheng, X., Klauda, J.B., Jo, S., Case, D.A., Jeong, J.C., Lemkul, J.A., Pande, V.S., Swails, J.M., Qi, Y., Eastman, P.K., Im, W., Brooks, C.L., Lee, J., Wei, S., MacKerell, A.D., Yeom, M.S., Buckner, J., 2015. CHARMM-GUI Input Generator for NAMD, GROMACS, AMBER, OpenMM, and CHARMM/OpenMM Simulations Using the CHARMM36 Additive Force Field. J. Chem. Theory Comput. 12, 405-413. https://doi.org/10.1021/acs.jctc.5b00935

De Jonghe, C., Esselens, C., Kumar-Singh, S., Craessaerts, K., Serneels, S., Checler, F., Annaert, W., Van Broeckhoven, C., De Strooper, B., 2001. Pathogenic APP mutations near the $\gamma$ secretase cleavage site differentially affect A $\beta$ secretion and APP C-terminal fragment stability. Hum. Mol. Genet. 10, 1665-1671.

De Strooper, B., Iwatsubo, T., Wolfe, M.S., 2012. Presenilins and $\gamma$-secretase: structure, function, 
and role in Alzheimer Disease. Cold Spring Harb. Perspect. Med. 2, a006304. https://doi.org/10.1101/cshperspect.a006304

Dehury, B., Kepp, K.P., 2020. Membrane dynamics of $\gamma$-secretase with the anterior pharynx-defective 1B subunit. J. Cell. Biochem.

Dehury, B., Tang, N., Blundell, T.L., Kepp, K.P., 2019a. Structure and dynamics of $\gamma$-secretase with presenilin 2 compared to presenilin 1. RSC Adv. 9, 20901-20916. https://doi.org/10.1039/c9ra02623a

Dehury, B., Tang, N., Kepp, K.P., 2019b. Insights into membrane-bound presenilin 2 from allatom molecular dynamics simulations. J. Biomol. Struct. Dyn. 1-15.

Dehury, B., Tang, N., Kepp, K.P., 2019c. Molecular dynamics of C99-bound $\gamma$-secretase reveal two binding modes with distinct compactness, stability, and active-site retention: Implications for $A \beta$ production. Biochem. J. 476, 1173-1189. https://doi.org/10.1042/BCJ20190023

DeLano, W.L., 2002. Pymol: An open-source molecular graphics tool. CCP4 Newsl. Protein Crystallogr. 40, 82-92.

Eckman, C.B., Mehta, N.D., Crook, R., Perez-tur, J., Prihar, G., Pfeiffer, E., Graff-Radford, N., Hinder, P., Yager, D., Zenk, B., 1997. A new pathogenic mutation in the APP gene (I716V) increases the relative proportion of A $\beta 42$ (43). Hum. Mol. Genet. 6, 2087-2089.

Eisenberg, D., Jucker, M., 2012. The amyloid state of proteins in human diseases. Cell 148, 11881203. https://doi.org/10.1016/j.cell.2012.02.022

Essmann, U., Perera, L., Berkowitz, M.L., Darden, T., Lee, H., Pedersen, L.G., 1995. A smooth particle mesh Ewald method. J. Chem. Phys. 103, 8577-8593. https://doi.org/10.1063/1.470117

Ferreira, T.M., Coreta-Gomes, F., Ollila, O.H.S., Moreno, M.J., Vaz, W.L.C., Topgaard, D., 2013. 
Cholesterol and POPC segmental order parameters in lipid membranes: solid state $1 \mathrm{H}-13 \mathrm{C}$ NMR and MD simulation studies. Phys. Chem. Chem. Phys. 15, 1976-1989.

Fukumori, A., Fluhrer, R., Steiner, H., Haass, C., 2010. Three-amino acid spacing of presenilin endoproteolysis suggests a general stepwise cleavage of gamma-secretase-mediated intramembrane proteolysis. J. Neurosci. 30, 7853-7862. https://doi.org/10.1523/JNEUROSCI.1443-10.2010

Fukumori, A., Steiner, H., 2016. Substrate recruitment of $\gamma$-secretase and mechanism of clinical presenilin mutations revealed by photoaffinity mapping. EMBO J. e201694151.

Götz, A., Mylonas, N., Högel, P., Silber, M., Heinel, H., Menig, S., Vogel, A., Feyrer, H., Huster, D., Luy, B., 2019. Modulating hinge flexibility in the APP transmembrane domain alters $\gamma-$ secretase cleavage. Biophys. J. 116, 2103-2120.

Hardy, J.A., Higgins, G.A., 1992. Alzheimer's disease: the amyloid cascade hypothesis. Science (80-. ). 256, 184-185.

Heilig, E.A., Xia, W., Shen, J., Kelleher, R.J., 2010. A presenilin-1 mutation identified in familial Alzheimer disease with cotton wool plaques causes a nearly complete loss of $\gamma$-secretase activity. J. Biol. Chem. 285, 22350-22359.

Hekkelman, M.L., te Beek, T.A.H., Pettifer, S.R., Thorne, D., Attwood, T.K., Vriend, G., 2010. WIWS: A protein structure bioinformatics web service collection. Nucleic Acids Res. 38, 719-723. https://doi.org/10.1093/nar/gkq453

Herl, L., Thomas, A. V, Lill, C.M., Banks, M., Deng, A., Jones, P.B., Spoelgen, R., Hyman, B.T., Berezovska, O., 2009. Mutations in amyloid precursor protein affect its interactions with presenilin/ $\gamma$-secretase. Mol. Cell. Neurosci. 41, 166-174.

Hess, B., Bekker, H., Berendsen, H.J.C., Fraaije, J.G.E.M., 1997. LINCS: A Linear Constraint Solver for molecular simulations. J. Comput. Chem. 18, 1463-1472. 
https://doi.org/10.1002/(SICI)1096-987X(199709)18:12<1463::AID-JCC4>3.0.CO;2-H

Hitzenberger, M., Zacharias, M., 2019. $\gamma$-Secretase Studied by Atomistic Molecular Dynamics

Simulations: Global Dynamics, Enzyme Activation, Water Distribution and Lipid Binding.

Front. Chem. 6, 640. https://doi.org/10.3389/fchem.2018.00640

Holtzman, D.M., Mandelkow, E., Selkoe, D.J., 2012. Alzheimer disease in 2020. Cold Spring

Harb. Perspect. Med. 2, a011585. https://doi.org/10.1101/cshperspect.a011585

Huang, J., Rauscher, S., Nawrocki, G., Ran, T., Feig, M., De Groot, B.L., Grubmüller, H.,

MacKerell, A.D., 2016. CHARMM36m: An improved force field for folded and intrinsically disordered proteins. Nat. Methods 14, 71-73. https://doi.org/10.1038/nmeth.4067

Humphrey, W., Dalke, A., Schulten, K., 1996. VMD: visual molecular dynamics. J. Mol. Graph.

14, 33-38. https://doi.org/10.1016/0263-7855(96)00018-5

Jensen, K.P., 2008. Improved interaction potentials for charged residues in proteins. J. Phys.

Chem. B 112, 1820-1827. https://doi.org/10.1021/jp077700b

Jorgensen, W.L., Chandrasekhar, J., Madura, J.D., Impey, R.W., Klein, M.L., 1983. Comparison of simple potential functions for simulating liquid water. J. Chem. Phys. 79, 926. https://doi.org/10.1063/1.445869

Jurkiewicz, P., Cwiklik, L., Vojtíšková, A., Jungwirth, P., Hof, M., 2012. Structure, dynamics, and hydration of POPC/POPS bilayers suspended in $\mathrm{NaCl}, \mathrm{KCl}$, and $\mathrm{CsCl}$ solutions. Biochim. Biophys. Acta (BBA)-Biomembranes 1818, 609-616.

Kamp, F., Winkler, E., Trambauer, J., Ebke, A., Fluhrer, R., Steiner, H., 2015. Intramembrane proteolysis of $\beta$-amyloid precursor protein by $\gamma$-secretase is an unusually slow process. Biophys. J. 108, 1229-1237. https://doi.org/10.1016/j.bpj.2014.12.045

Kelleher, R.J., Shen, J., 2017. Presenilin-1 mutations and Alzheimer's disease. Proc. Natl. Acad. Sci. 114, 629-631. 
Kepp, K.P., 2017. Ten Challenges of the Amyloid Hypothesis of Alzheimer's Disease. J.

Alzheimer's Dis. 55, 447-457. https://doi.org/10.3233/JAD-160550

Kepp, K.P., 2016. Alzheimer's disease due to loss of function: A new synthesis of the available data. Prog. Neurobiol. 143, 36-60. https://doi.org/10.1016/j.pneurobio.2016.06.004

Klauda, J.B., Venable, R.M., Freites, J.A., O’Connor, J.W., Tobias, D.J., Mondragon-Ramirez, C., Vorobyov, I., MacKerell, A.D., Pastor, R.W., 2010. Update of the CHARMM All-Atom Additive Force Field for Lipids: Validation on Six Lipid Types. J. Phys. Chem. B 114, 78307843. https://doi.org/10.1021/jp101759q

Knappenberger, K.S., Tian, G., Ye, X., Sobotka-Briner, C., Ghanekar, S. V, Greenberg, B.D., Scott, C.W., 2004. Mechanism of gamma-secretase cleavage activation: is gamma-secretase regulated through autoinhibition involving the presenilin-1 exon 9 loop? Biochemistry 43, 6208-18. https://doi.org/10.1021/bi036072v

Kretner, B., Fukumori, A., Kuhn, P., Pérez-Revuelta, B.I., Lichtenthaler, S.F., Haass, C., Steiner, H., 2013. Important functional role of residue $\mathrm{x}$ of the presenilin Gx GD protease active site motif for APP substrate cleavage specificity and substrate selectivity of $\gamma$-secretase. J. Neurochem. 125, 144-156.

Kretner, B., Trambauer, J., Fukumori, A., Mielke, J., Kuhn, P., Kremmer, E., Giese, A., Lichtenthaler, S.F., Haass, C., Arzberger, T., Steiner, H., 2016. Generation and deposition of A $\beta 43$ by the virtually inactive presenilin- 1 L435F mutant contradicts the presenilin loss-of-function hypothesis of Alzheimer's disease. EMBO Mol. Med. 8, 458-465. https://doi.org/10.15252/emmm.201505952

Langosch, D., Steiner, H., 2017. Substrate processing in intramembrane proteolysis by $\gamma$ secretase-the role of protein dynamics. Biol. Chem. 398, 441-453. https://doi.org/10.1515/hsz-2016-0269 
Lemere, C.A., Lopera, F., Kosik, K.S., Lendon, C.L., Ossa, J., Saido, T.C., Yamaguchi, H., Ruiz, A., Martinez, A., Madrigal, L., Hincapie, L., Arango, J.C., Anthony, D.C., Koo, E.H., Goate, A.M., Selkoe, D.J., 1996. The E280A presenilin 1 Alzheimer mutation produces increased A beta 42 deposition and severe cerebellar pathology. Nat Med 2, 1146-1150. https://doi.org/10.1038/nm1096-1146

Li, N., Liu, K., Qiu, Y., Ren, Z., Dai, R., Deng, Y., Qing, H., 2016. Effect of presenilin mutations on APP cleavage; Insights into the pathogenesis of FAD. Front. Aging Neurosci. 8, 51. https://doi.org/10.3389/fnagi.2016.00051

Li, S., Zhang, W., Han, W., 2017. Initial Substrate Binding of $\gamma$-Secretase: The Role of Substrate Flexibility. ACS Chem. Neurosci. 8, 1279-1290. https://doi.org/10.1021/acschemneuro.6b00425

Li, X., Dang, S., Yan, C., Gong, X., Wang, J., Shi, Y., 2013. Structure of a presenilin family intramembrane aspartate protease. Nature 493, 56-61. https://doi.org/10.1038/nature11801

Lomize, A.L., Pogozheva, I.D., Lomize, M.A., Mosberg, H.I., 2006. Positioning of proteins in membranes: A computational approach. Protein Sci. 15, 1318-1333. https://doi.org/10.1110/ps.062126106

Lomize, M.A., Pogozheva, I.D., Joo, H., Mosberg, H.I., Lomize, A.L., 2012. OPM database and PPM web server: Resources for positioning of proteins in membranes. Nucleic Acids Res. 40, D370-D376. https://doi.org/10.1093/nar/gkr703

Lopera, F., Ardilla, A., Martínez, A., Madrigal, L., Arango-Viana, J.C., Lemere, C.A., ArangoLasprilla, J.C., Hincapié, L., Arcos-Burgos, M., Ossa, J.E., 1997. Clinical features of earlyonset Alzheimer disease in a large kindred with an E280A presenilin-1 mutation. Jama 277, 793-799.

Lu, P., Bai, X., Ma, D., Xie, T., Yan, C., Sun, L., Yang, G., Zhao, Y., Zhou, R., Scheres, S.H.W., 
Shi, Y., 2014. Three-dimensional structure of human $\gamma$-secretase. Nature 512, 166-170. https://doi.org/10.1038/nature 13567

Martyna, G.J., Klein, M.L., Tuckerman, M., 1992. Nosé-Hoover chains: The canonical ensemble via continuous dynamics. J. Chem. Phys. 97, 2635-2643. https://doi.org/10.1063/1.463940 Masters, C.L., Gajdusek, D.C., Gibbs, C.J.J., 1981. The familial occurrence of Creutzfeldt-Jakob disease and Alzheimer's disease. Brain 104, 535-558.

Mehra, R., Dehury, B., Kepp, K.P., 2020. Cryo-temperature effects on membrane protein structure and dynamics. Phys. Chem. Chem. Phys. 22, 5427-5438.

Mehra, R., Kepp, K.P., 2020. Identification of Structural Calcium Binding Sites in MembraneBound Presenilin 1 and 2. J. Phys. Chem. B 124, 4697-4711. https://doi.org/10.1021/acs.jpcb.0c01712

Mehra, R., Kepp, K.P., 2019. Computational analysis of Alzheimer-causing mutations in amyloid precursor protein and presenilin 1. Arch. Biochem. Biophys. 678, 108168. https://doi.org/https://doi.org/10.1016/j.abb.2019.108168

Moliaka, Y.K., Grigorenko, A., Madera, D., Rogaev, E.I., 2004. Impas 1 possesses endoproteolytic activity against multipass membrane protein substrate cleaving the presenilin 1 holoprotein. FEBS Lett. 557, 185-192.

Morishima-Kawashima, M., 2014. Molecular mechanism of the intramembrane cleavage of the $\beta$ carboxyl terminal fragment of amyloid precursor protein by $\gamma$-secretase. Front. Physiol. 5, 463.

Murayama, O., Tomita, T., Nihonmatsu, N., Murayama, M., Sun, X., Honda, T., Iwatsubo, T., Takashima, A., 1999. Enhancement of amyloid $\beta 42$ secretion by 28 different presenilin 1 mutations of familial Alzheimer's disease. Neurosci. Lett. 265, 61-63. https://doi.org/10.1016/S0304-3940(99)00187-1 
Oakley, D.H., Chung, M., Klickstein, N., Commins, C., Hyman, B.T., Frosch, M.P., 2020. The Alzheimer Disease-Causing Presenilin-1 L435F Mutation Causes Increased Production of Soluble A 343 Species in Patient-Derived iPSC-Neurons, Closely Mimicking Matched Patient Brain Tissue. J. Neuropathol. Exp. Neurol. 79, 592-604.

Ohki, Y., Shimada, N., Tominaga, A., Osawa, S., Higo, T., Yokoshima, S., Fukuyama, T., Tomita, T., Iwatsubo, T., 2014. Binding of longer $A \beta$ to transmembrane domain 1 of presenilin 1 impacts on A $\beta 42$ generation. Mol. Neurodegener. 9, 7.

Okochi, M., Tagami, S., Yanagida, K., Takami, M., Kodama, T.S., Mori, K., Nakayama, T., Ihara, Y., Takeda, M., 2013. $\gamma$-Secretase Modulators and Presenilin 1 Mutants Act Differently on Presenilin $/ \gamma$-Secretase Function to Cleave A $\beta 42$ and A $\beta 43$. Cell Rep. 3, 42-51. https://doi.org/10.1016/j.celrep.2012.11.028

Páll, S., Hess, B., 2013. A flexible algorithm for calculating pair interactions on SIMD architectures. Comput. Phys. Commun. 184, 2641-2650. https://doi.org/10.1016/j.cpc.2013.06.003

Parrinello, M., Rahman, A., 1981. Polymorphic Transitions in Single Crystals: a New Molecular Dynamics Method. J. Appl. Phys. 52, 7182-7190. https://doi.org/10.1063/1.328693

Pérez-Revuelta, B.I., Fukumori, A., Lammich, S., Yamasaki, A., Haass, C., Steiner, H., 2010. Requirement for small side chain residues within the GxGD-motif of presenilin for $\gamma$-secretase substrate cleavage. J. Neurochem. 112, 940-950.

Pester, O., Barrett, P.J., Hornburg, D., Hornburg, P., Pröbstle, R., Widmaier, S., Kutzner, C., Dürrbaum, M., Kapurniotu, A., Sanders, C.R., Scharnagl, C., Langosch, D., 2013. The backbone dynamics of the amyloid precursor protein transmembrane helix provides a rationale for the sequential cleavage mechanism of $\gamma$-secretase. J. Am. Chem. Soc. 135, 1317-1329. https://doi.org/10.1021/ja3112093 
Petit, D., Hitzenberger, M., Lismont, S., Zoltowska, K.M., Ryan, N.S., Mercken, M., Bischoff, F., Zacharias, M., Chávez-Gutiérrez, L., 2019. Extracellular interface between APP and Nicastrin regulates $A \beta$ length and response to $\gamma$-secretase modulators. EMBO J. 38, e101494.

Ross, C., Nizami, B., Glenister, M., Sheik Amamuddy, O., Atilgan, A.R., Atilgan, C., Tastan Bishop, Ö., 2018. MODE-TASK: large-scale protein motion tools. Bioinformatics 34, 37593763.

Sato, C., Takagi, S., Tomita, T., Iwatsubo, T., 2008. The C-Terminal PAL Motif and Transmembrane Domain 9 of Presenilin 1 Are Involved in the Formation of the Catalytic Pore of the $\gamma$-Secretase. J. Neurosci. 28, 6264-6271. https://doi.org/10.1523/JNEUROSCI.1163-08.2008

Saura, C.A., Choi, S.-Y., Beglopoulos, V., Malkani, S., Zhang, D., Shankaranarayana Rao, B.S., Chattarji, S., Kelleher, R.J. 3rd, Kandel, E.R., Duff, K., Kirkwood, A., Shen, J., 2004. Loss of presenilin function causes impairments of memory and synaptic plasticity followed by agedependent neurodegeneration. Neuron 42, 23-36.

Scheuner, D., Eckman, C., Jensen, M., Song, X., Citron, M., Suzuki, N., Bird, T.D., Hardy, J., Hutton, M., Kukull, W., Larson, E., Levy-Lahad, E., Viitanen, M., Peskind, E., Poorkaj, P., Schellenberg, G., Tanzi, R., Wasco, W., Lannfelt, L., Selkoe, D., Younkin, S., 1996. Secreted amyloid beta-protein similar to that in the senile plaques of Alzheimer's disease is increased in vivo by the presenilin 1 and 2 and APP mutations linked to familial Alzheimer's disease. Nat. Med. 2, 864-870. https://doi.org/10.1038/nm0896-864

Seelig, J., Waespe-Sarcevic, N., 1978. Molecular order in cis and trans unsaturated phospholipid bilayers. Biochemistry 17, 3310-3315.

Selkoe, D.J., 2001. Alzheimer's disease: genes, proteins, and therapy. Physiol. Rev. 81, 741-766. Selkoe, D.J., Hardy, J., 2016. The amyloid hypothesis of Alzheimer's disease at 25 years. EMBO 
Mol. Med. 8, 595-608. https://doi.org/10.15252/emmm.201606210

Sepulveda-Falla, D., Glatzel, M., Lopera, F., 2012. Phenotypic profile of early-onset familial

Alzheimer's disease caused by presenilin-1 E280A mutation. J. Alzheimer's Dis. 32, 1-12. https://doi.org/10.3233/JAD-2012-120907

Shen, J., Kelleher, R.J., 2007. The presenilin hypothesis of Alzheimer's disease: evidence for a loss-of-function pathogenic mechanism. Proc. Natl. Acad. Sci. U. S. A. 104, 403-409. https://doi.org/10.1073/pnas.0608332104

Somavarapu, A.K., Kepp, K.P., 2017. Membrane Dynamics of $\gamma$-Secretase Provides a Molecular Basis for $\beta$-Amyloid Binding and Processing. ACS Chem. Neurosci. 8, 2424-2436. https://doi.org/10.1021/acschemneuro.7b00208

Somavarapu, A.K., Kepp, K.P., 2016a. The dynamic mechanism of presenilin-1 function: Sensitive gate dynamics and loop unplugging control protein access. Neurobiol. Dis. 89, 147-156. https://doi.org/10.1016/j.nbd.2016.02.008

Somavarapu, A.K., Kepp, K.P., 2016b. Loss of stability and hydrophobicity of presenilin 1 mutations causing Alzheimer's Disease. J. Neurochem. 137, 101-111. https://doi.org/10.1111/jnc. 13535

Soto-Mercado, V., Mendivil-Perez, M., Velez-Pardo, C., Lopera, F., Jimenez-Del-Rio, M., 2020. Cholinergic-like neurons carrying PSEN1 E280A mutation from familial Alzheimer's disease reveal intraneuronal sAPP $\beta$ fragments accumulation, hyperphosphorylation of TAU, oxidative stress, apoptosis and $\mathrm{Ca} 2+$ dysregulation: Therapeutic implications. PLoS One 15, e0221669.

Steiner, H., Fukumori, A., Tagami, S., Okochi, M., 2018. Making the final cut: pathogenic amyloid- $\beta$ peptide generation by $\gamma$-secretase. Cell Stress $2,292-310$.

https://doi.org/10.15698/cst2018.11.162 
Steiner, H., Kostka, M., Romig, H., Basset, G., Pesold, B., Hardy, J., Capell, A., Meyn, L., Grim, M.L., Baumeister, R., 2000. Glycine 384 is required for presenilin-1 function and is conserved in bacterial polytopic aspartyl proteases. Nat. Cell Biol. 2, 848-851.

Sun, L., Zhao, L., Yang, G., Yan, C., Zhou, R., Zhou, X., Xie, T., Zhao, Y., Wu, S., Li, X., Shi, Y., 2015. Structural basis of human $\gamma$-secretase assembly. Proc. Natl. Acad. Sci. U. S. A. 112, 6003-6008. https://doi.org/10.1073/pnas.1506242112

Sun, L., Zhou, R., Yang, G., Shi, Y., 2016. Analysis of 138 pathogenic mutations in presenilin-1 on the in vitro production of $A \beta 42$ and $A \beta 40$ peptides by $\gamma$-secretase. Proc. Natl. Acad. Sci. 114, E476-E485. https://doi.org/10.1073/pnas.1618657114

Szaruga, M., Munteanu, B., Lismont, S., Veugelen, S., Horré, K., Mercken, M., Saido, T.C., Ryan, N.S., De Vos, T., Savvides, S.N., Gallardo, R., Schymkowitz, J., Rousseau, F., Fox, N.C., Hopf, C., Strooper, B. De, 2017. Alzheimer's-Causing Mutations Shift A $\beta$ Length by Destabilizing $\gamma$-Secretase-A $\beta$ n Interactions. Cell 170, 443-456.

Szaruga, M., Veugelen, S., Benurwar, M., Lismont, S., Sepulveda-Falla, D., Lleo, A., Ryan, N.S., Lashley, T., Fox, N.C., Murayama, S., 2015. Qualitative changes in human $\gamma$-secretase underlie familial Alzheimer's disease. J. Exp. Med. 212, 2003-2013.

Takagi-Niidome, S., Sasaki, T., Osawa, S., Sato, T., Morishima, K., Cai, T., Iwatsubo, T., Tomita, T., 2015. Cooperative Roles of Hydrophilic Loop 1 and the C-Terminus of Presenilin 1 in the Substrate-Gating Mechanism of $\gamma$-Secretase. J. Neurosci. 35, 2646-2656. https://doi.org/10.1523/JNEUROSCI.3164-14.2015

Takagi, S., Tominaga, A., Sato, C., Tomita, T., Iwatsubo, T., 2010. Participation of transmembrane domain 1 of presenilin 1 in the catalytic pore structure of the $\gamma$-secretase. J. Neurosci. 30, 15943-15950.

Takami, M., Nagashima, Y., Sano, Y., Ishihara, S., Morishima-Kawashima, M., Funamoto, S., 
Ihara, Y., 2009. $\gamma$-Secretase: successive tripeptide and tetrapeptide release from the transmembrane domain of $\beta$-carboxyl terminal fragment. J. Neurosci. 29, 13042-13052. https://doi.org/10.1523/JNEUROSCI.2362-09.2009

Tambini, M.D., D’Adamio, L., 2020. Knock-in rats with homozygous PSEN1L435F Alzheimer mutation are viable and show selective $\gamma$-secretase activity loss causing low A $\beta 40 / 42$ and high Aß43. J. Biol. Chem. 295, 7442-7451.

Tang, N., Dehury, B., Kepp, K.P., 2019. Computing the Pathogenicity of Alzheimer's Disease Presenilin 1 Mutations. J. Chem. Inf. Model. 59, 858-870. https://doi.org/10.1021/acs.jcim.8b00896

Tang, N., Kepp, K.P., 2018. A $\beta 42 / A \beta 40$ ratios of presenilin 1 mutations correlate with clinical onset of Alzheimer's disease. J. Alzheimer's Dis. 66, 939-945.

Tang, N., Somavarapu, A.K., Kepp, K.P., 2018. Molecular Recipe for $\gamma$-Secretase Modulation from Computational Analysis of 60 Active Compounds. ACS Omega 3, 18078-18088. https://doi.org/10.1021/acsomega.8b02196

Tanzi, R.E., 2012. The genetics of Alzheimer disease. Cold Spring Harb. Perspect. Med. 2, a006296-. https://doi.org/10.1101/cshperspect.a006296

Tanzi, R.E., Bertram, L., 2005. Twenty years of the Alzheimer's disease amyloid hypothesis: a genetic perspective. Cell 120, 545-555.

Theuns, J., Marjaux, E., Vandenbulcke, M., Van Laere, K., Kumar-Singh, S., Bormans, G., Brouwers, N., Van den Broeck, M., Vennekens, K., Corsmit, E., 2006. Alzheimer dementia caused by a novel mutation located in the APP C-terminal intracytosolic fragment. Hum. Mutat. 27, 888-896.

Tiwari, M.K., Kepp, K.P., 2016. $\beta$-Amyloid pathogenesis: Chemical properties versus cellular levels. Alzheimer's Dement. 12, 184-194. https://doi.org/10.1016/j.jalz.2015.06.1895 
Trambauer, J., Rodríguez Sarmiento, R.M., Fukumori, A., Feederle, R., Baumann, K., Steiner, H., 2020. Aß43-producing PS 1 FAD mutants cause altered substrate interactions and respond to $\gamma$-secretase modulation. EMBO Rep. 21, e47996. https://doi.org/10.15252/embr.201947996 van Es, J.H., van Gijn, M.E., Riccio, O., van den Born, M., Vooijsss, M., Begthel, H., Cozijnsen, M., Robine, S., Winton, D.J., Radtke, F., Clevers, H., 2005. Notch/gamma-secretase inhibition turns prolliferative cells in intestinal crypts and adenomas into goblet cells. Nature 435, 959-963.

Veugelen, S., Saito, T., Saido, T.C., Chávez-Gutiérrez, L., De Strooper, B., 2016. Familial Alzheimer's Disease Mutations in Presenilin Generate Amyloidogenic A $\beta$ Peptide Seeds. Neuron 90, 410-416. https://doi.org/10.1016/j.neuron.2016.03.010

Wang, J., Beher, D., Nyborg, A.C., Shearman, M.S., Golde, T.E., Goate, A., 2006. C-terminal PAL motif of presenilin and presenilin homologues required for normal active site conformation. J. Neurochem. 96, 218-227. https://doi.org/10.1111/j.1471-4159.2005.03548.x

Wolfe, M.S., 2020. Unraveling the complexity of $\gamma$-secretase, in: Seminars in Cell \& Developmental Biology. Elsevier.

Xia, D., Watanabe, H., Wu, B., Lee, S.H., Li, Y., Tsvetkov, E., Bolshakov, V.Y., Shen, J., Kelleher III, R.J., 2015. Presenilin-1 knockin mice reveal loss-of-function mechanism for familial Alzheimer's disease. Neuron 85, 967-981.

Yamasaki, A., Eimer, S., Okochi, M., Smialowska, A., Kaether, C., Baumeister, R., Haass, C., Steiner, H., 2006. The GxGD motif of presenilin contributes to catalytic function and substrate identification of $\gamma$-secretase. J. Neurosci. 26, 3821-3828.

Yang, G., Zhou, R., Zhou, Q., Guo, X., Yan, C., Ke, M., Lei, J., Shi, Y., 2019. Structural basis of Notch recognition by human $\gamma$-secretase. Nature 565, 192-197.

https://doi.org/10.1038/s41586-018-0813-8 
Zhou, R., Yang, G., Guo, X., Zhou, Q., Lei, J., Shi, Y., 2019. Recognition of the amyloid precursor protein by human $\gamma$-secretase. Science (80-. ). 363, eaaw0930. https://doi.org/10.1126/science.aaw0930

Zhuang, X., Dávila-Contreras, E.M., Beaven, A.H., Im, W., Klauda, J.B., 2016. An extensive simulation study of lipid bilayer properties with different head groups, acyl chain lengths, and chain saturations. Biochim. Biophys. Acta - Biomembr. 1858, 3093-3104. https://doi.org/10.1016/j.bbamem.2016.09.016

\section{Author statement}

Budheswar Dehury: Methodology, data production, writing first paper draft Arun Somavarapu: Methodology, model generation, visualization, Kasper P. Kepp: Conceptualization, project design, project supervision, writing of paper

\section{Competing Interests statement}

All authors hereby declare that they have no competing interests, neither financial nor nonfinancial, related to this work.

- Alzheimer's disease-causing mutations change the way $\gamma$-secretase produces $A \beta$

- The structure of five prominent mutations is reported from computational models

- The mutations increase the space and variability in the substrate binding site

- Our study provides atomic detail into how Alzheimer-causing mutations work 

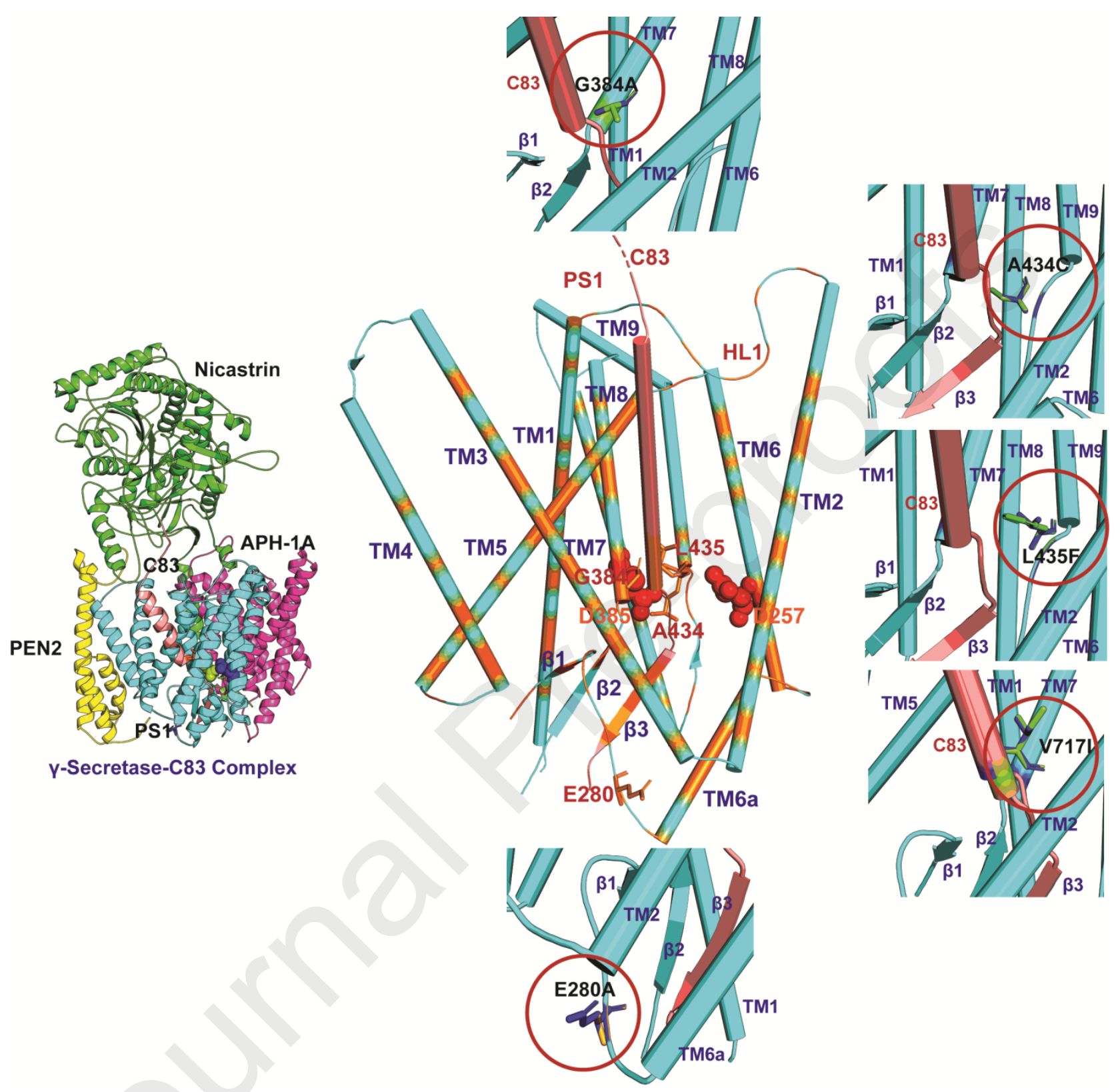


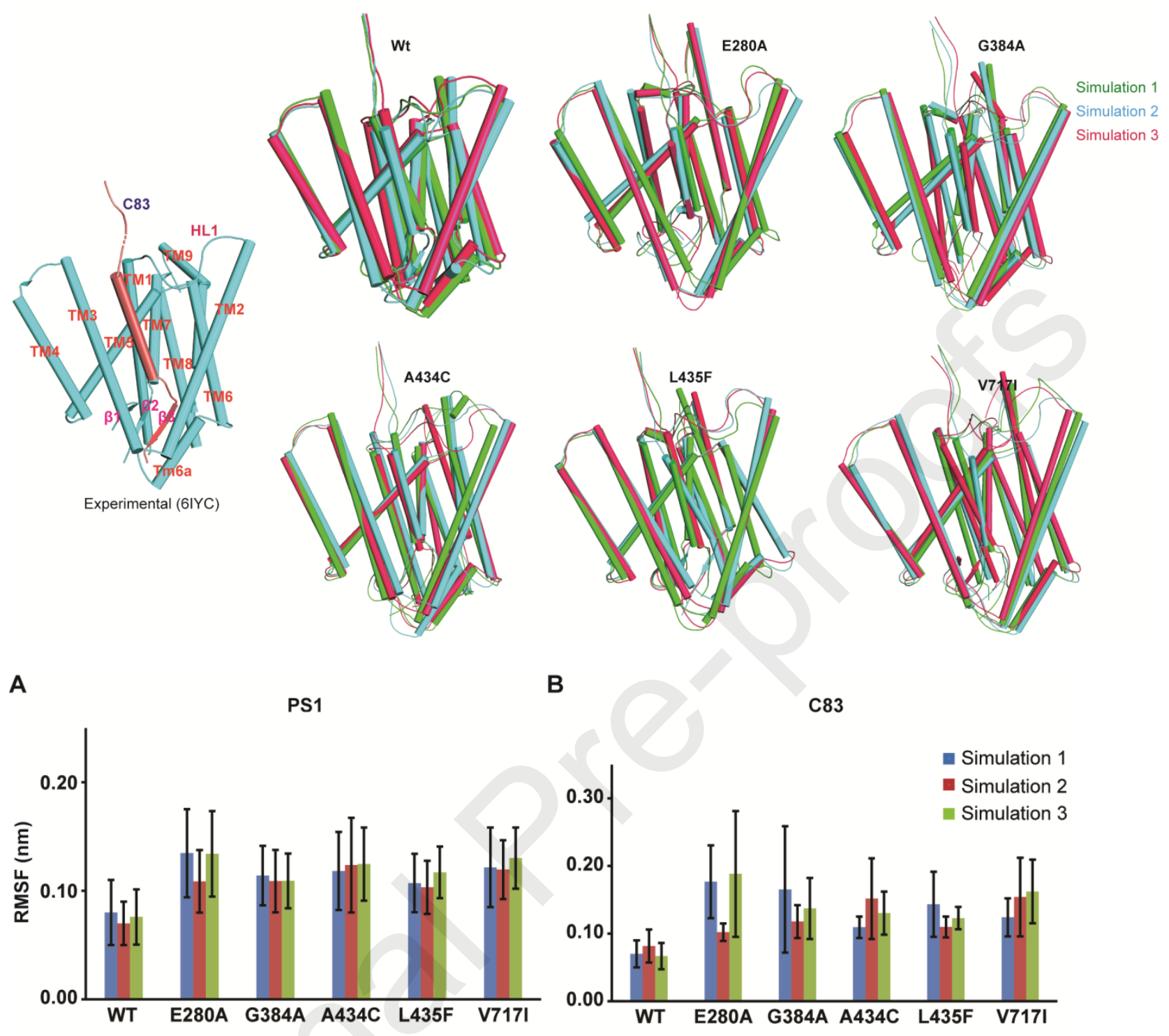


A
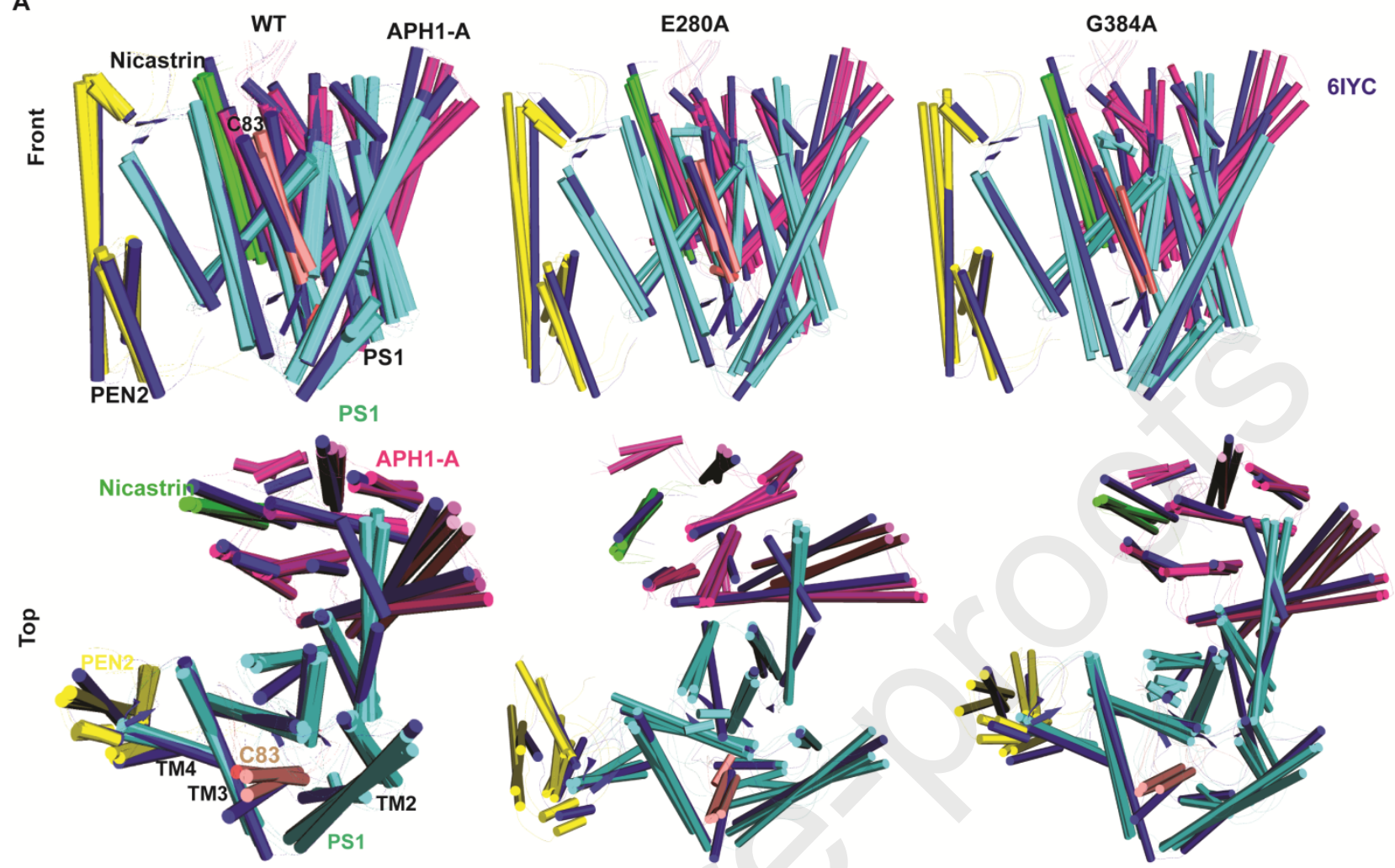

B
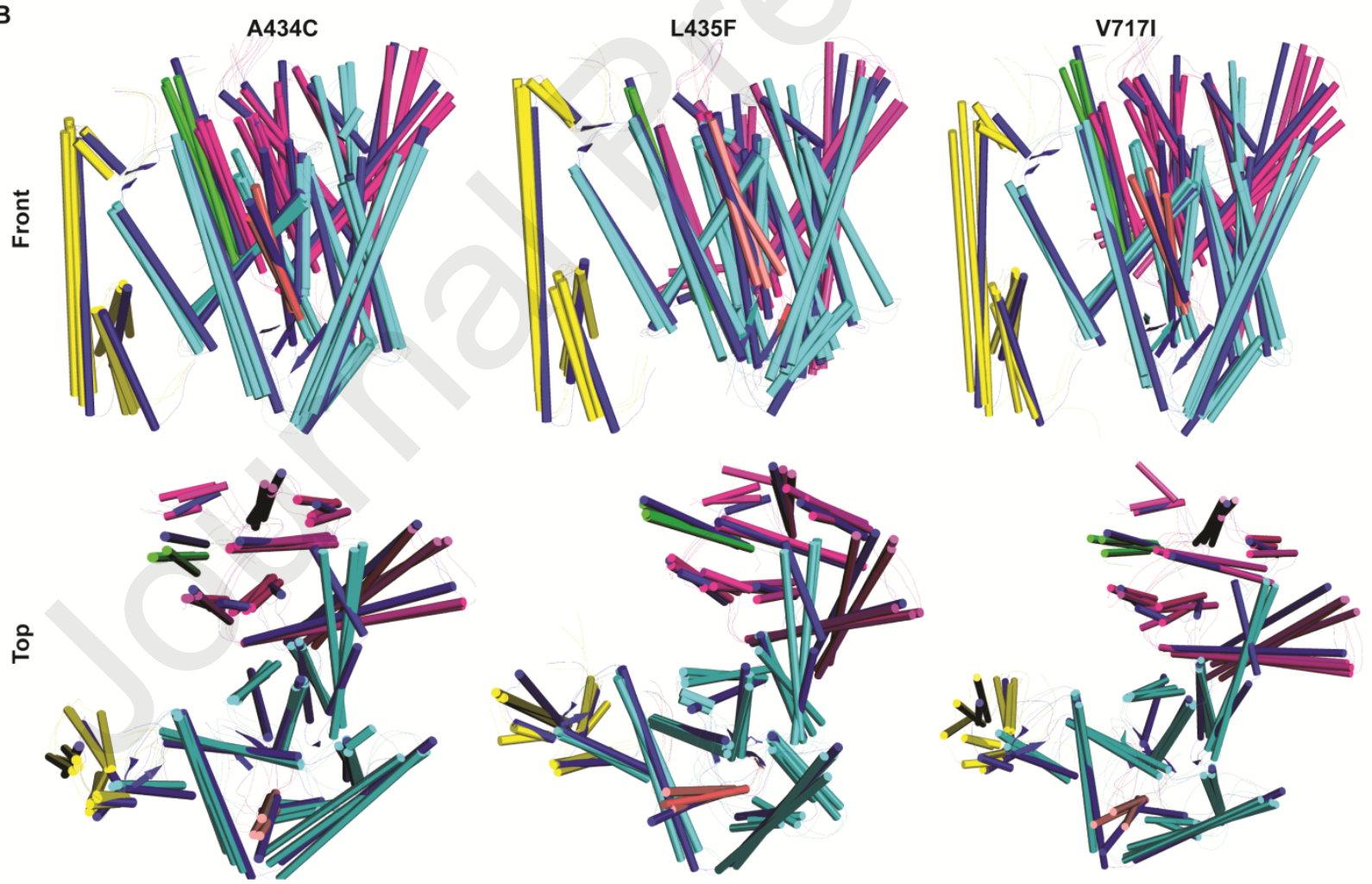

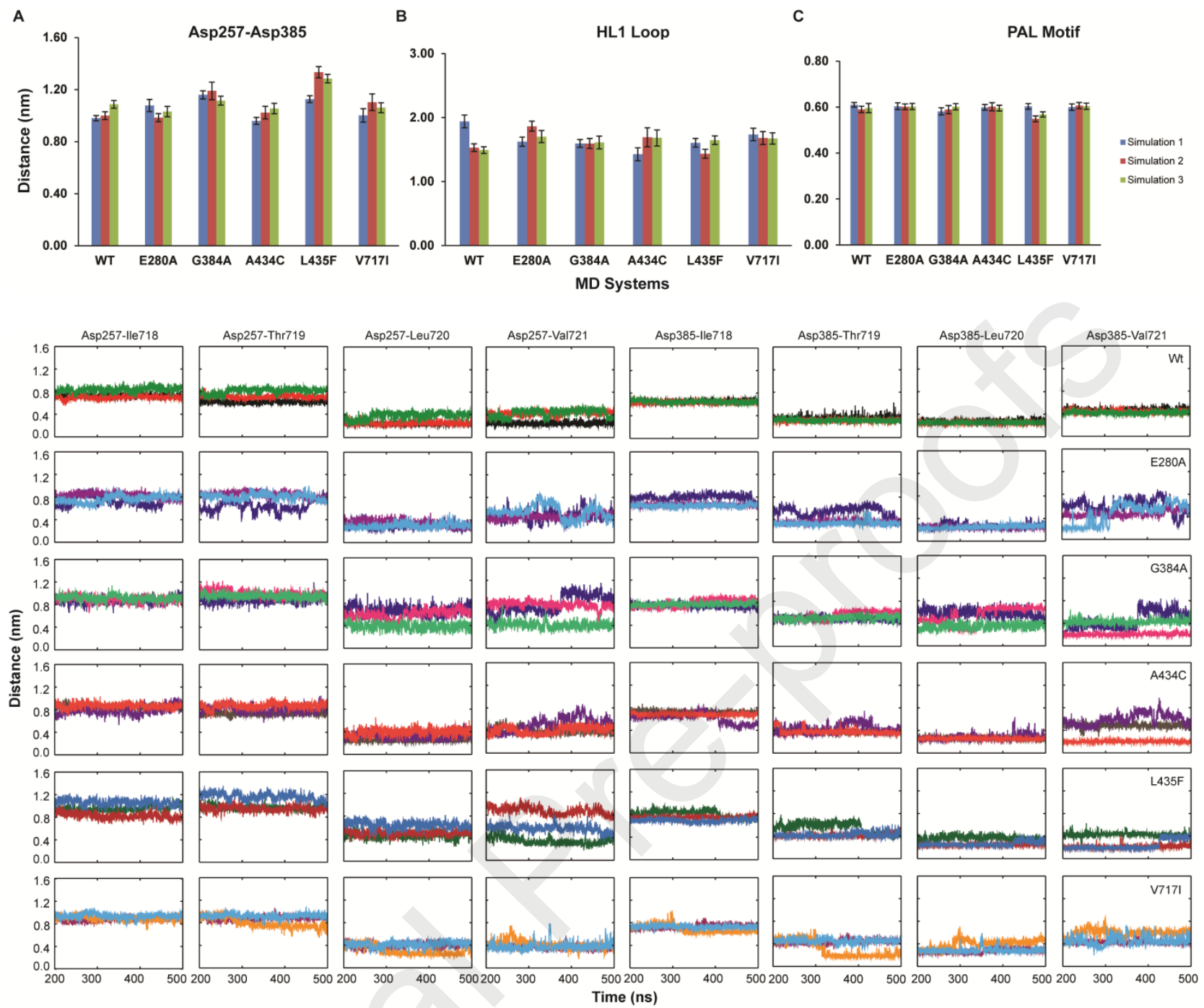


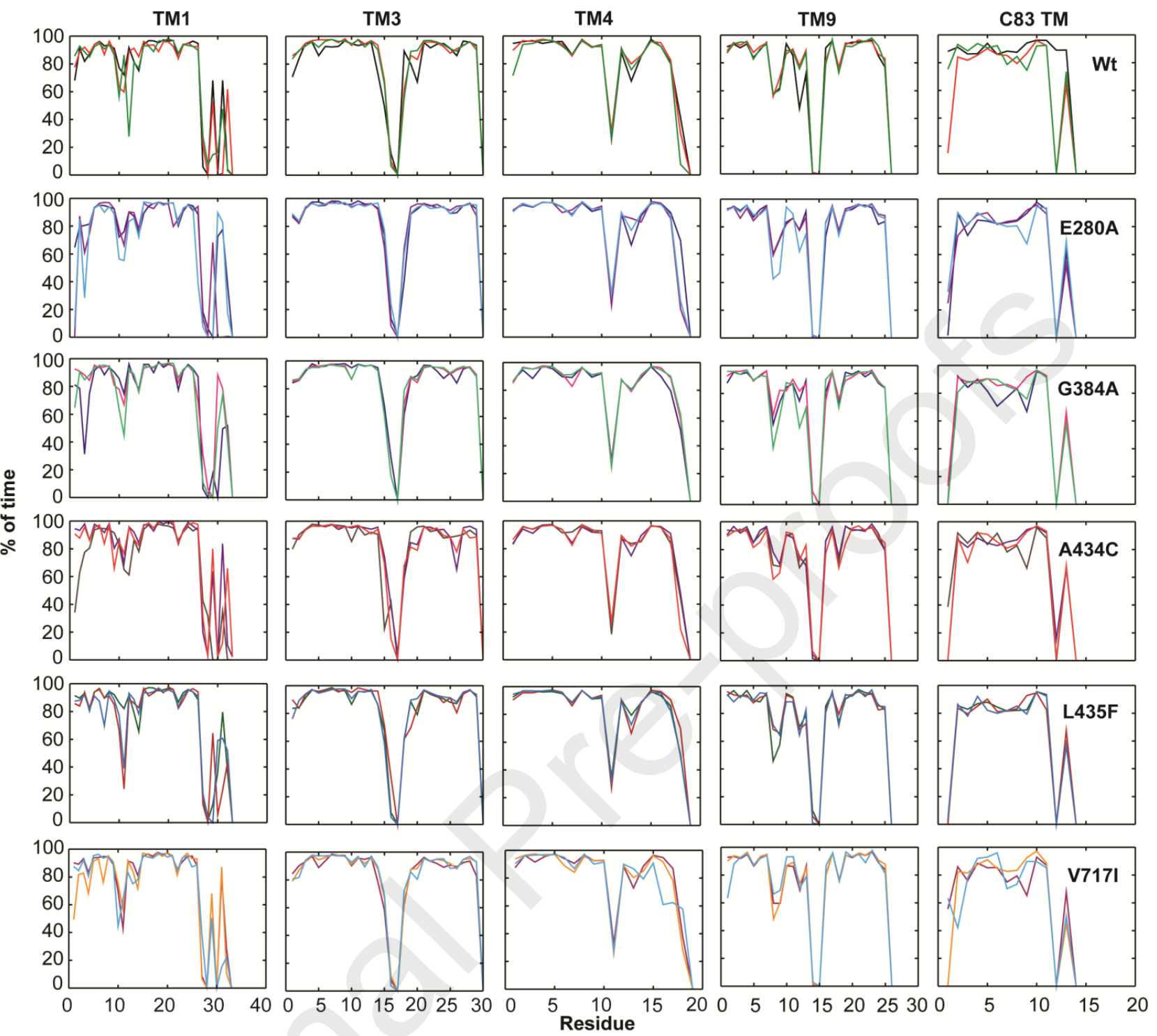




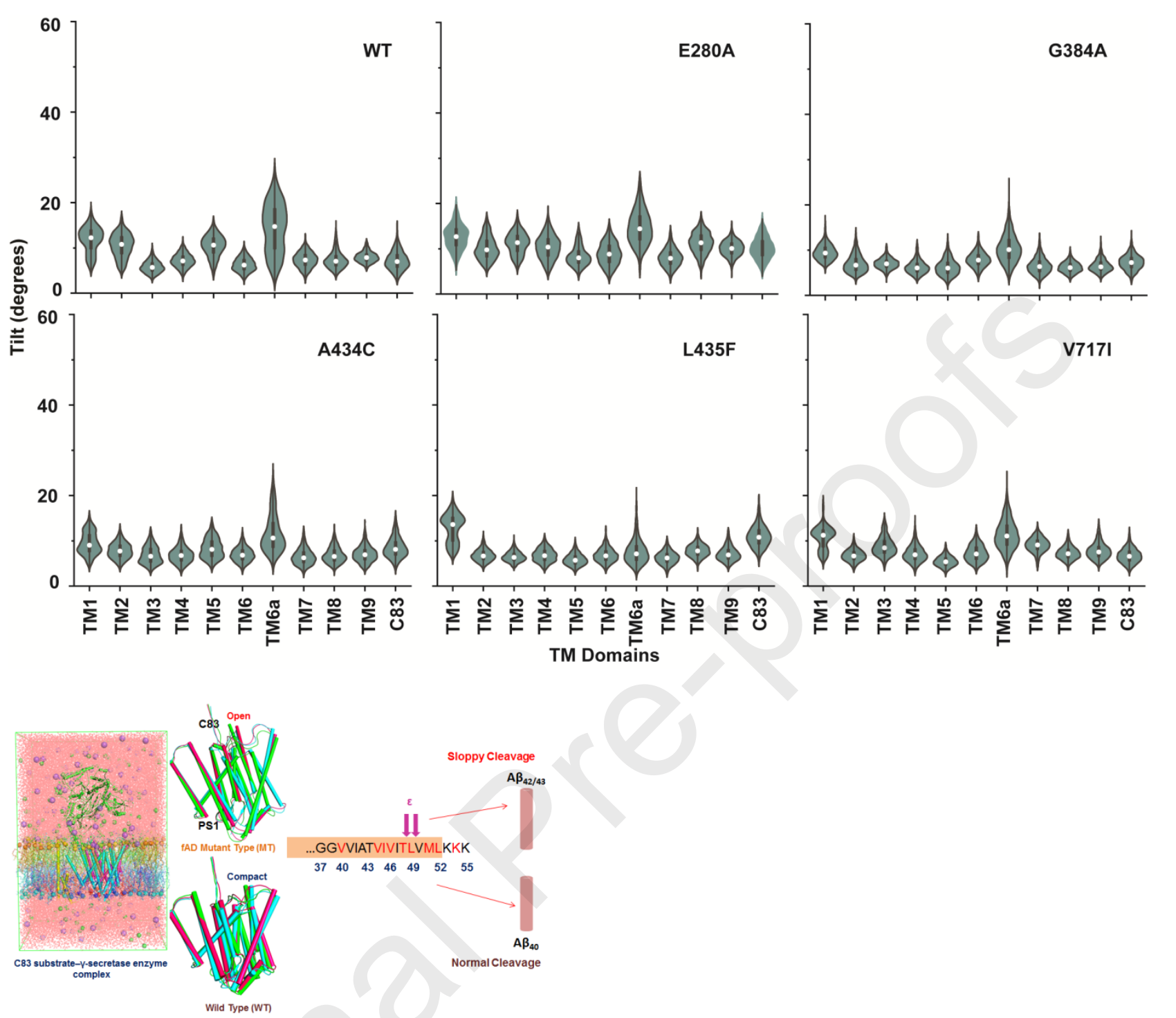

53 